\title{
Synthesis and Solvatochromic Behavior of Zwitterionic Donor- Bridge-Acceptor Systems with Oligo(p-phenylene) Spacers
}

\author{
Irina Zharinova ${ }^{a}$ (i) \\ Nicolau Saker Neto ${ }^{\text {a }}$ \\ Tze Cin Owyong ${ }^{\mathrm{a}}$ (i) \\ Jonathan M. White ${ }^{\mathrm{a}}$ (i) \\ Wallace W. H. Wong*a (i) \\ a ARC Centre of Excellence in Exciton Science, School of Chemistry, Bio21 Institute,
University of Melbourne, Parkville, Victoria 3010, Australia \\ wwhwong@unimelb.edu.au \\ Dedicated to Prof. Peter Bäuerle on his 65th birthday.
}

Received: 15.01.2021

Accepted after revision: 1.02.2021

DOI: 10.1055/s-0041-1725075; Art ID: om-21-0006oa

License terms: CC

(c) 2021. The Author(s). This is an open access article published by Thieme under the terms of the Creative Commons Attribution-NonDerivative-NonCommercial License, permitting copying and reproduction so long as the original work is given appropriate credit. Contents may not be used for commercial purposes, or adapted, remixed, transformed or built upon. (https://creativecommons.org/licenses/by-nc-nd/4.0/)

Abstract Oligo(p-phenylene)s with a donor phenol group and an acceptor pyridinium moiety separated by one and two $p$-phenylene units were synthesized by the linear iterative Suzuki-Miyaura coupling method using aryl nonaflates as effective coupling reagents. Zwitterionic forms of these push-pull molecules were generated upon deprotonation of the phenol leading to large redshifts in absorbance maxima. UV-vis absorbance studies also revealed strong dependence of the band position on solvent polarity: a smooth bathochromic shift can be observed with the decrease of the solvent polarity. The molecule with one $p$-phenylene bridging unit showed the strongest solvatochromic characteristics in the series, spanning the range of $167 \mathrm{~nm}$ while moving from polar water to less polar $\mathrm{N}, \mathrm{N}$-dimethylformamide. The magnitude of this shift was close to Reichardt's dye - one of the most solvatochromic organic dyes known.

Key words conjugated molecules, cross-coupling, electron donoracceptor systems, solvatochromism

\section{Introduction}

Push-pull organic molecules containing electron-rich and electron-poor moieties have seen application in sensors as well as optical and electronic devices. ${ }^{1-4}$ They are discrete, functionally desymmetrized molecules, bearing electron donor and acceptor substituents as end-groups, separated by a $\pi$-conjugated bridge. Such organic systems can have large nonlinear optical (NLO) coefficients with ultra-fast responses originating from the almost instantaneous electronic polarization. ${ }^{5-7}$ The $\pi$-conjugated bridges in these molecules are usually aromatic spacers, such as thienylene, phenylenevinylene, and phenylene units. ${ }^{2,8,9}$

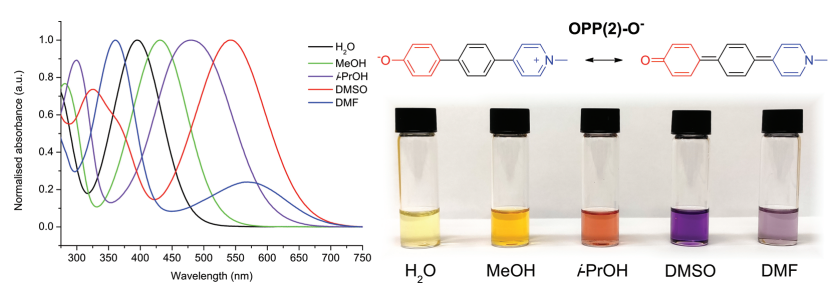

One of the widely studied representatives of push-pull systems, Brooker's merocyanine (BM) (Figure 1), is composed of a strong donor phenolate group, an acceptor pyridinium group, and a vinyl linkage in between. It is known for its pronounced negative solvatochromic behavior [the hypsochromic shift of the absorbance maxima $\left(\lambda_{\max }\right)$ with the increase of the polarity of solvent] and its ease of preparation. ${ }^{10,11}$ According to UV-vis spectroscopy measurements for $\mathbf{B M}$, the absorbance maximum undergoes a large redshift while going from highly polar water $(444 \mathrm{~nm})$ to moderately polar pyridine $(605 \mathrm{~nm})$, a difference of $161 \mathrm{~nm}$, accompanied by a color change from yellow to blue. ${ }^{11}$ However, for sufficiently low polarity solvents (e.g. hydrocarbons), this solvatochromic behavior is reversed, and slight positive solvatochromism is observed instead. ${ }^{12}$ Interaction between the oxygen atom of the merocyanine and the hydrogen atom of hydrogen bond donor solvents was found to be essential for the significant solvatochromic shift, as this bonding stabilized the zwitterionic form of the molecule. ${ }^{13}$

Another example displaying a negative solvatochromism moving from water (394 nm) to acetonitrile (472 nm) is 4-[N-

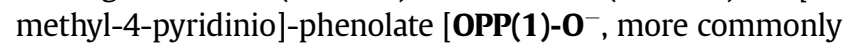
known as POMP], which is formed by directly attaching phenolate and pyridinium functionalities without any spacer (Figure 1). ${ }^{14}$ One more well-known compound similar to BM

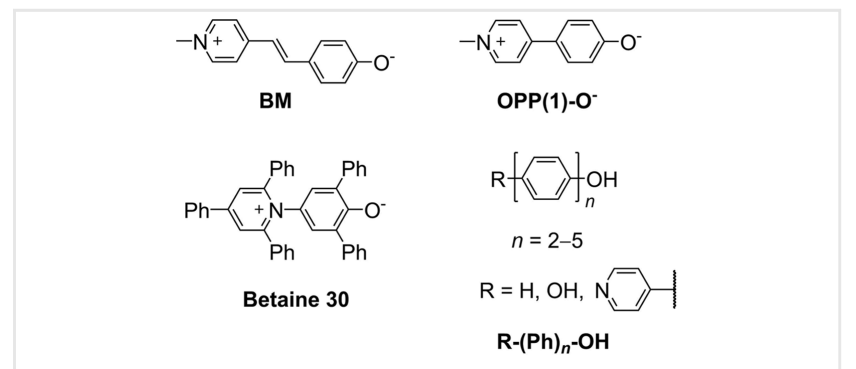

Figure 1 Some examples of organic molecules investigated for electrooptic applications. 
and $\mathbf{O P P}(\mathbf{1})-\mathbf{O}^{-}$is Reichardt's dye or Betaine $\mathbf{3 0}$ (Figure 1). ${ }^{3,15}$ This dye is extensively used as a probe for medium polarity. Betaine 30 is constructed by directly connecting the nitrogen atom of the pyridyl moiety to the phenolate ring. A polarity scale has been established based on this compound, where the parameter $E_{\mathrm{T}}(30)$ is defined as the molar electronic transition energy ( $\mathrm{kcal} \mathrm{mol}^{-1}$ ) of Reichardt's betaine. ${ }^{3}$ There is a linear correlation between the transition energies of $\mathbf{O P P}(\mathbf{1})-\mathbf{0}^{-}$and Betaine 30; however, the former compound has smaller solvatochromic shifts than Reichardt's dye and is therefore less effective as a polarity indicator. ${ }^{14}$

The conjugation of push-pull chromophores can be extended by using oligo( $p$-phenylene)s (OPPs). ${ }^{16,17}$ A series of OPPs with varying length and functionalized with one or two hydroxyl groups $\left[\mathbf{R}-(\mathbf{P h})_{\boldsymbol{n}} \mathbf{- O H}\right]$ has been reported previously (Figure 1). ${ }^{9}$ From UV-vis measurements for such systems, it was found that deprotonation leads to a bathochromic shift of the absorbance maximum by up to $80 \mathrm{~nm}$ in comparison to the protonated species. For the deprotonated forms of $\mathbf{R}-(\mathbf{P h})_{n}-\mathbf{O H}$ ( $\mathrm{R}=\mathrm{H}, \mathrm{OH} ; n=3-5)$, there was a shift towards larger wavelengths as the donor number ${ }^{18}$ of the solvent increased. The same behavior was also demonstrated in photoluminescence spectra. Therefore, by varying the solvent nature the emission wavelength of deprotonated OPPs can be tuned, which could be useful for the development of light-emitting materials. ${ }^{19,20}$ This work was then extended by attaching an electron-accepting pyridyl moiety on the opposite end of an OPP chain terminated with an electron-donating hydroxyl group $\left[\mathbf{P y}-(\mathbf{P h})_{\mathbf{2}} \mathbf{- O H}\right],{ }^{8}$ forming a donor-bridge-acceptor structure. In UV-vis spectra, the bathochromic shift of $118 \mathrm{~nm}$ was observed after treatment of a DMF solution with $\mathrm{NaH}^{8}$

The described zwitterionic molecules could be represented in both aromatic and quinoid forms. The ground electronic state of these molecules was dominated by the charge-separated aromatic form, while the excited state was described by the neutral quinoid form with decreased resonance energy upon intramolecular charge transfer. The donor-bridge-acceptor topology and, especially, the donor/acceptor strength of substituents are crucial for varying the relative energetics of both resonance forms. ${ }^{7}$

To be useful for commercial devices, the priority in the synthesis of chromophores is given to cost-effective and highyield chemical pathways. Of course, the synthetic approach for each class of NLO-chromophores could be different, but the molecules might involve similar fragments. A key to construct conjugated oligomers is to provide efficient carboncarbon bond formation. Development of the field of organometallic catalysts using transition metal-catalyzed reactions has attracted attention for the synthesis of conjugated molecules. Among a large variety of transition metal catalysts, well-known examples are nickel- or palladium-based complexes. ${ }^{21}$ In particular, Suzuki-Miyaura (SM) coupling $^{22}$ is an effective method for the synthesis of conjugated molecules with varying phenylene or other (hetero)aromatic units. Since its development, numerous improvements have been made with respect to reaction scope, application of various reaction substrates, lowering the catalyst loading, and ability to conduct reactions even at room temperature. $^{23,24}$

For synthesis of conjugated chromophores such as OPPs, aryl/heteroaryl halides and triflates are generally used as substrates for SM coupling. Due to moderate reactivity of aryl triflates and their high cost, aryl nonaflates have been proposed as an improved alternative. Moreover, the main triflating reagent, triflic anhydride, is extremely reactive even at $-78{ }^{\circ} \mathrm{C}$, which can lead to side reactions. Nonafluorobutanesulfonyl fluoride $\left(\mathrm{C}_{4} \mathrm{~F}_{9} \mathrm{SO}_{2} \mathrm{~F}, \mathrm{NfF}\right)$, as the most convenient precursor for nonaflates, is a milder reagent. It is also nontoxic, air-stable, and can be stored for a long time, ${ }^{25,26}$ whereas trifluoromethanesulfonyl fluoride is a poisonous gas. So far, only a few reports related to the application of aryl nonaflates in SM coupling have been published, where aryl/heteroaryl nonaflates have shown slightly higher reactivity and better yields compared to corresponding triflates. ${ }^{27-29}$

In this study, by extending the reported zwitterionic $\mathbf{O P P}(\mathbf{1})-\mathbf{0}^{-}$system with one and two $p$-phenylene bridging units, we introduce new OPPs: $\mathbf{O P P}(2)-\mathbf{0}^{-}$and $\mathbf{O P P}(\mathbf{3})-\mathbf{0}^{-}$ (Figure 2). The bridge selection was based on the structural simplicity and synthetic accessibility of OPPs and the similarity of the electron-poor pyridyl unit to the phenylene spacers of the chain. Additional substitutions were not sought to maintain as simple a system as possible and avoid confounding electronic effects. Figure 2 shows resonance structures of $\mathbf{O P P}(\boldsymbol{n})-\mathbf{0}^{-}(n=1-3)$ where the zwitterionic structures are of aromatic character and the neutral forms have quinoid character. A reliable synthetic strategy involving SM coupling and nonaflate chemistry was implemented thus allowing sequential elongation of the chain to produce the desired OPPs. We also examine solvatochromic characteristics of new systems, compare them with the earlier studied analogue, and elucidate the chain-length effect on obtained properties.

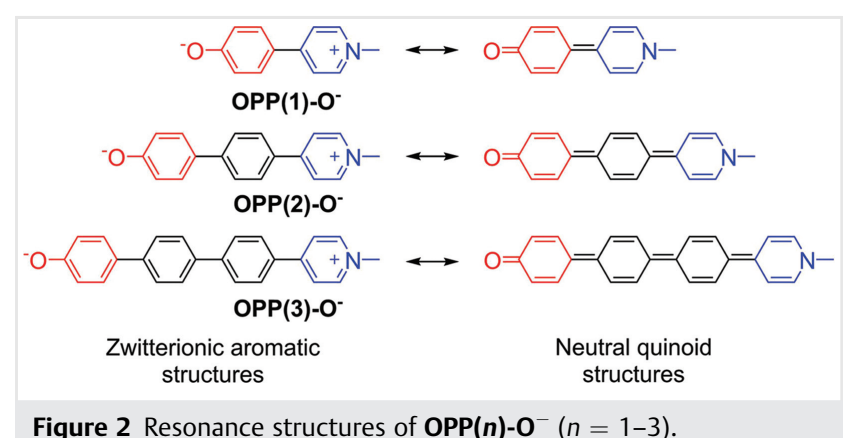




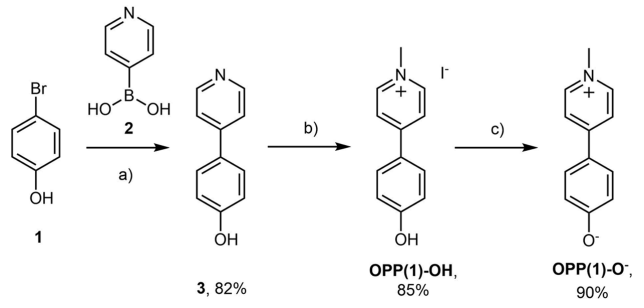

Scheme 1 Synthesis of $\mathrm{N}$-methylpyridinium phenolate $\mathbf{O P P}(1)-\mathbf{O}^{-}$: a) $\mathrm{Pd}_{2} \mathrm{dba}_{3}$ (2.5 mol\%), Cy $\mathrm{P}_{3} \mathrm{P} \cdot \mathrm{HBF}_{4}$ (6.0 mol\%), $\mathrm{K}_{3} \mathrm{PO}_{4}$ (1.7 equiv), 1,4-dioxane $/ \mathrm{H}_{2} \mathrm{O}(2 / 1, \mathrm{v} / \mathrm{v}), 100^{\circ} \mathrm{C}, 16 \mathrm{~h}$; b) Mel (4.0 equiv), acetone, 55 ${ }^{\circ} \mathrm{C}, 16 \mathrm{~h}$; c) $\mathrm{NBu}_{4} \mathrm{OH}, \mathrm{MeOH}$, r.t., $15 \mathrm{~min}$.

\section{Results and Discussion}

\section{Synthesis}

The previously reported molecule ${ }^{14} \mathbf{O P P}(\mathbf{1})-\mathbf{0}^{-}$was synthesized in three consecutive steps (Scheme 1), starting from SM coupling of unprotected 4-bromophenol (1) and 4-pyridinylboronic acid (2). The initially applied SM reaction conditions were $\mathrm{Pd}_{2} \mathrm{dba}_{3}(0.5 \mathrm{~mol} \%)$ and $t \mathrm{Bu}_{3} \mathrm{P} \cdot \mathrm{HBF}_{4}(1.2 \mathrm{~mol} \%)$ as a catalyst system, $\mathrm{KF} \cdot 2 \mathrm{H}_{2} \mathrm{O}$ as a base, and THF at $60{ }^{\circ} \mathrm{C},{ }^{30}$ but unsatisfactory conversion was observed, with a large amount of starting material remaining. After variation of reaction parameters including ligand $\left(t \mathrm{Bu}_{3} \mathrm{P} \cdot \mathrm{HBF}_{4}, \mathrm{Cy}_{3} \mathrm{P} \cdot \mathrm{HBF}_{4}, \mathrm{SPhos}\right)$, base (KF, $\mathrm{KF} \cdot 2 \mathrm{H}_{2} \mathrm{O}$, $\mathrm{K}_{3} \mathrm{PO}_{4}$ ), solvent (THF, toluene, 1,4-dioxane, $\mathrm{H}_{2} \mathrm{O}$ ), and reaction temperature, the optimal combination was found to be $\mathrm{Pd}_{2} \mathrm{dba}_{3}(0.5 \mathrm{~mol} \%), \mathrm{Cy}_{3} \mathrm{P} \cdot \mathrm{HBF}_{4}(1.2 \mathrm{~mol} \%)$, and $\mathrm{K}_{3} \mathrm{PO}_{4}$ in 1,4-dioxane $/ \mathrm{H}_{2} \mathrm{O}(2 / 1, \mathrm{v} / \mathrm{v})$ at $100{ }^{\circ} \mathrm{C},{ }^{31}$ which resulted in a yield of $82 \%$. $N$-Methylation of $\mathbf{3}$ followed by deprotonation produced $\mathbf{O P P}(\mathbf{1})-\mathbf{O}^{-}$in excellent yield (Scheme 1).

Linear iterative coupling with SM coupling chemistry was used as a method for extension of OPP bridges. ${ }^{8,9,16}$ The starting 4-bromophenol (1) was benzylated to protect the phenol functionality that would ultimately be present in the final compound, and then coupled with 4-hydroxyphenylboronic acid (5) to form a simple biphenyl unit $\mathbf{6}$ in 70\% yield (Scheme 2). In the first step of the cycle (Scheme 2), the phenol functionality of the substrate (6 or 8), unreactive in SM coupling, is activated by conversion to the nonaflate ( $\mathbf{7}$ or $\mathbf{9}$ ) using NfF. ${ }^{25,27,29}$ Thus, in the second step the activated substrate couples with 4-hydroxyphenylboronic acid (5). As a result, one unit adds to the sequence at each cycle. The phenol group is recovered at the end of the cycle, and can then be activated in the next one.

$\mathrm{N}$-Methylation reactions proceeded with high yields (98\%) resulting in yellow precipitates of biphenyl and terphenylmethylpyridinium iodides (12 and 13) (Scheme 3). To further proceed, multiple debenzylation conditions were tested on 12, such as TMS-I, ${ }^{32} \mathrm{Pd} / \mathrm{C}$ hydrogenation, ${ }^{33} \mathrm{SOCl}_{2},{ }^{34}$ and $\mathrm{NiCl}_{2} \cdot 6 \mathrm{H}_{2} \mathrm{O} / \mathrm{NaBH}_{4} \cdot{ }^{35}$ However, these showed only the presence of the unreacted starting material. Other trials ${ }^{36}$ with LiI, LiCl, trifluoroacetic acid (TFA), formic acid, methanesulfonic acid, and molten pyridinium hydrochloride resulted in partial conversion to the product with a hydroxyl group, as determined by ESI-MS. To ensure full debenzylation of 12 and 13, rather harsh conditions were applied, with stirring in excess $\mathrm{HBr} / \mathrm{AcOH}(33 \mathrm{wt} \%$ ) at room temperature. $^{37}$ ESI-MS confirmed conversion of the benzyl ether to an acetate group, as well as small amounts of the protonated final products $\mathbf{O P P}(\mathbf{2})-\mathbf{O H}$

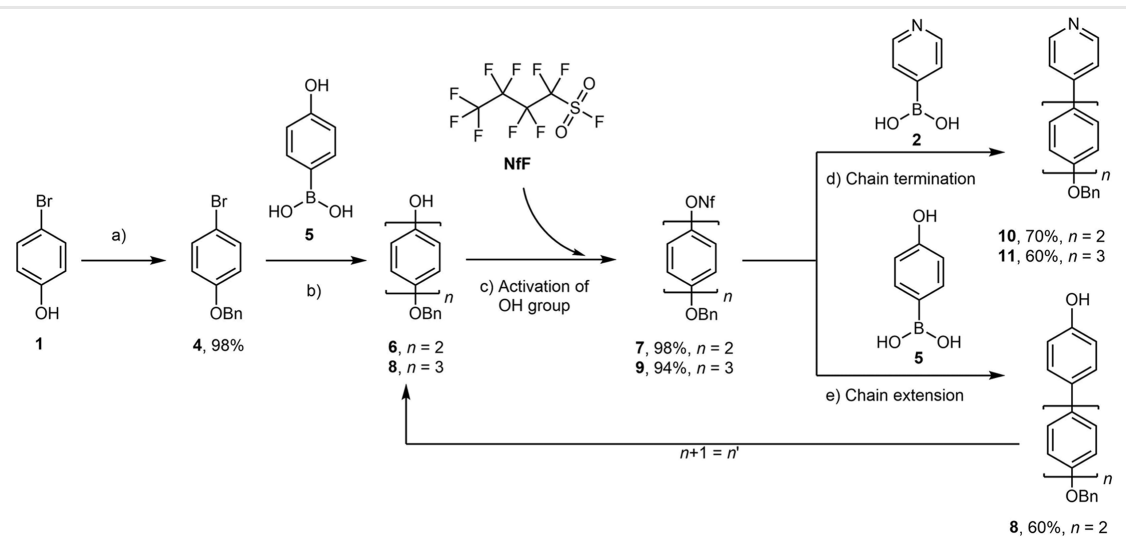

Scheme 2 Synthesis of OPPs via linear iterative coupling: a) $\mathrm{BnCl}$ (1.1 equiv), $\mathrm{K}_{2} \mathrm{CO}_{3}$ (3.0 equiv), $\mathrm{KI}\left(10 \mathrm{~mol} \%\right.$ ), acetone, $60^{\circ} \mathrm{C}, 5 \mathrm{~h}$; b) $\mathrm{Pd}_{2} \mathrm{dba}_{3}(0.5 \mathrm{~mol}$ \%), $\mathrm{Cy}_{3} \mathrm{P} \cdot \mathrm{HBF}_{4}(1.2 \mathrm{~mol} \%), \mathrm{K}_{3} \mathrm{PO}_{4}$ (1.5 equiv), 1,4-dioxane $\left./ \mathrm{H}_{2} \mathrm{O}(2 / 1, \mathrm{v} / \mathrm{v}), 100^{\circ} \mathrm{C}, 16 \mathrm{~h} ; \mathrm{c}\right) \mathrm{NfF}\left(1.2\right.$ equiv), $\mathrm{Et}{ }_{3} \mathrm{~N}$ (1.5 equiv), DCM, r.t. for $n=2$ or DMF, 60 ${ }^{\circ} \mathrm{C}, 16 \mathrm{~h}$ for $n=3$; d) $n=2: \mathrm{Pd}_{2} \mathrm{dba}_{3}(0.5 \mathrm{~mol} \%), \mathrm{Cy}_{3} \mathrm{P} \cdot \mathrm{HBF}_{4}$ (1.2 mol\%), $\mathrm{K}_{3} \mathrm{PO}_{4}$ (1.7 equiv), 1,4-dioxane/ $\mathrm{H}_{2} \mathrm{O}(2 / 1, \mathrm{v} / \mathrm{v}), 100{ }^{\circ} \mathrm{C}, 16 \mathrm{~h} ; n=3: \mathrm{Pd}_{2} \mathrm{dba}_{3}$ (2.5 mol\%), $\mathrm{Cy}_{3} \mathrm{P} \cdot \mathrm{HBF}_{4}$ (6.0 mol\%), $\mathrm{K}_{3} \mathrm{PO}_{4}$ (1.7 equiv), THF/H $\mathrm{H}_{2} \mathrm{O}$ (10/1, v/v), $100{ }^{\circ} \mathrm{C}, 16 \mathrm{~h}$; e) $\mathrm{Pd}_{2} \mathrm{dba}_{3}(0.5 \mathrm{~mol} \%), \mathrm{Cy}_{3} \mathrm{P} \cdot \mathrm{HBF}_{4}\left(1.2 \mathrm{~mol}^{\circ}\right), \mathrm{K}_{3} \mathrm{PO}_{4}(1.7$ equiv), 1,4-dioxane $/ \mathrm{H}_{2} \mathrm{O}(2 / 1, \mathrm{v} / \mathrm{v}), 100{ }^{\circ} \mathrm{C}, 16 \mathrm{~h}$. 


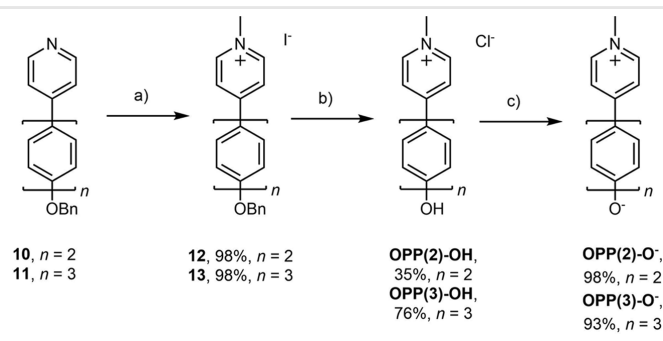

Scheme $3 \mathrm{~N}$-Methylation and deprotection of extended OPPs: a) Mel [5.5 equiv $(n=2)$ or 4.4 equiv $(n=3)$ ], DMF, $60^{\circ} \mathrm{C}, 48 \mathrm{~h}$; b) $\mathrm{HBr} / \mathrm{AcOH}$ (excess), r.t., 16 h; $\mathrm{HCl}$ (excess), $\mathrm{MeOH}$, reflux; c) Aqueous $\mathrm{NaOH}$, r.t.

and $\mathbf{O P P}(\mathbf{3})-\mathbf{O H}$, with no detectable trace of remaining benzylated material.

In the case of biphenylmethylpyridinium iodide 12, the obtained mixture of the acetate (14) and $\mathbf{O P P}(2)-\mathbf{O H}$ was subjected to base deprotection (Scheme 4). ${ }^{1} \mathrm{H}$ NMR spectroscopy revealed the presence of the main deprotonated molecule $\mathbf{O P P}(2)-\mathbf{0}^{-}$as well as a byproduct with similar structure. Analysis of the byproduct signals in the ${ }^{1} \mathrm{H}$ NMR spectrum showed that its most shielded doublet had half the integration of all other byproduct aryl signals, suggesting substitution of the hydrogen atom ortho to the phenolate, and ${ }^{13} \mathrm{C}$ NMR spectroscopy displayed an unexpectedly shielded signal at $93 \mathrm{ppm}$, consistent with an aryl iodide (iodobenzene ${ }^{13} \mathrm{C}-\mathrm{I}$ signal $\left.=95 \mathrm{ppm}\right)$. ESI-MS confirmed the presence of 0 -iodo-substituted teraryl (15) as a side product, matching the theoretical mass $\left([\mathrm{M}+\mathrm{H}]^{+} m / z=388.0193\right)$.

One of the explanations for the 0 -iodination observed is that the solution of $\mathrm{HBr} / \mathrm{AcOH}$ used could degrade slowly producing some amount of $\mathrm{Br}_{2}$, evidenced by the light orange color of the acid mixture. During the debenzylation of the $\mathrm{N}$-methylpyridinium iodide salt, $\mathrm{Br}_{2}$ could partially oxidize the iodide to molecular $\mathrm{I}_{2}$ and the triiodide anion $\mathrm{I}_{3}{ }^{-}$.

The subsequent basic deprotection conditions lead to the formation of phenolates, which are highly electron-rich and thus allowed electrophilic 0 -iodination to occur.

To avoid the undesirable electrophilic iodination, the workup procedure was modified in order to remove any iodine/triiodide traces. The solids obtained after the $\mathrm{HBr} / \mathrm{AcOH}$ reaction were washed with a sodium metabisulfite solution as a reducing agent. An acidic deacetylation pathway

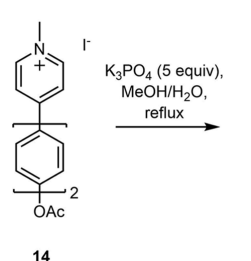

14

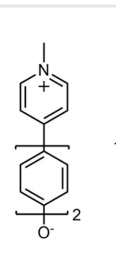

OPP(2)-O-

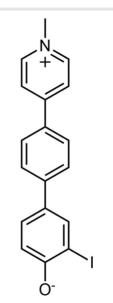

15
Scheme 4 Deacetylation procedure using $\mathrm{K}_{3} \mathrm{PO}_{4}$. was used and followed by a deprotonation step. To ensure a uniform counterion for all species, the obtained deprotonated forms were treated with aqueous $\mathrm{HCl}$ to produce the chloride salts $\mathbf{O P P}(2)-\mathbf{O H}$ and $\mathbf{O P P ( 3 ) - 0 H}$ with 35\% and 76\% yields, and the compounds were stored in this form for prolonged periods. When desired, the substances were subjected to a final deprotonation with aqueous $\mathrm{NaOH}$, with almost quantitative conversion to $\mathbf{O P P}(2)-\mathbf{0}^{-}$and $\mathbf{O P P}(\mathbf{3})-\mathbf{0}^{-}$(Scheme 3 ).

All obtained intermediates and final products were characterized by ${ }^{1} \mathrm{H}$ NMR [except $\mathbf{O P P}(3)-\mathbf{O}^{-}$due to the low solubility] and ${ }^{13} \mathrm{C}$ NMR [except 11, OPP(2)-0 $\mathbf{0}^{-}$, and OPP (3) $-\mathbf{0}^{-}$due to the low solubility] spectroscopy, mass spectrometry, and FT-IR.

\section{Structural Characterization}

${ }^{1} \mathrm{H}$ NMR spectroscopy in DMSO- $d_{6}$ (collected at $25{ }^{\circ} \mathrm{C}$, $\sim 10 \mathrm{mmol} / \mathrm{L}$ ) confirmed the presence of the phenol functionalities of $\mathbf{O P P}(\boldsymbol{n})-\mathbf{O H}(n=1-3)$. Upon treatment with the base, the solubility of the deprotonated forms OPP (n)-0 $\mathbf{O}^{-}(n=1-3)$ drops dramatically making NMR characterization difficult [see the Supporting Information (SI)].

The ${ }^{1} \mathrm{H}$ NMR spectrum of $\mathbf{O P P}(2)-\mathbf{O H}$ showing a set of six doublets integrating to two and the most deshielded singlet integrating as one corresponds to the phenol hydroxyl. The ${ }^{1} \mathrm{H}$ NMR spectrum of $\mathbf{O P P}(2)-\mathbf{O}^{-}$(collected at $60{ }^{\circ} \mathrm{C}$ ) shows a $0.4 \mathrm{ppm}$ shift for the most shielded doublet upon deprotonation and disappearance of the $\mathrm{OH}$ signal (Figure 3).

The crystal structures of $\mathbf{O P P}(\mathbf{1})-\mathbf{O H}$ and $\mathbf{O P P}(\mathbf{1})-\mathbf{O}^{-}$ have been reported previously. ${ }^{38}$ In this work, single crystals of the elongated oligomers were obtained by slow diffusion of diethyl ether vapor into a solution of sodium methoxide in methanol or DMSO solution of compounds $\mathbf{O P P}(2)-\mathbf{O H}$ and OPP(3)-OH. ORTEP representations of the obtained crystal structures are depicted in Figure 4 and derived parameters are given in Table S1 (SI). ${ }^{39}$ Comparison of the crystal structure for $\left[\mathbf{O P P}(2)-\mathbf{O}^{-}\right]_{2} \cdot \mathbf{H C l}$ was complicated by the fact that the unit cell contained two equivalent molecules sharing one hydrogen atom as well as one chloride counterion. Thus, the diffraction parameters obtained referred neither to the fully deprotonated OPP (2)-0 $\mathbf{O}^{-}$nor the fully protonated $\mathbf{O P P}(\mathbf{2})-\mathbf{O H}$ molecules, but rather an in-between state. The structure of $\mathbf{O P P}(\mathbf{3})-\mathbf{O H}$ is fully protonated and has a chloride counterion. The $\mathrm{C}-\mathrm{O}$ bond lengths for the obtained teraryl and quateraryl compounds [1.335(2) $\AA$ and 1.364(3) $\AA$ ] are closer to that of $\mathbf{O P P}(\mathbf{1})-\mathbf{O H}[1.363(6) \AA]$ indicating rather aromatic character of the structures, whereas the $\mathrm{C}-\mathrm{O}$ bond length of 1.305(2) $\AA$ in $\mathbf{O P P}(\mathbf{1})-\mathbf{0}^{-}$is shorter. The dihedral angles between the pyridinium moieties and their adjacent rings for $\left[\mathbf{O P P}(\mathbf{2})-\mathbf{0}^{-}\right]_{2} \cdot \mathbf{H C l}$ and $\mathbf{O P P}(\mathbf{3})-\mathbf{O H}$ are similar $\left(15.8^{\circ}\right.$ and $\left.15.0^{\circ}\right)$. Meanwhile, this value is lower for $\mathbf{O P P}(\mathbf{1})-\mathbf{0}^{-}\left(5.7^{\circ}\right)$, 


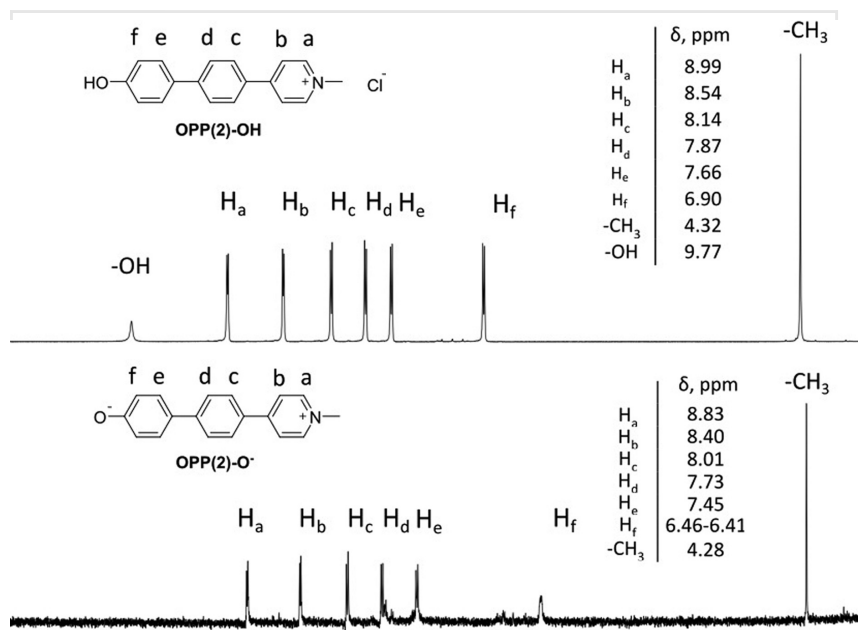

$\begin{array}{llllllllllllll}10.5 & 10.0 & 9.5 & 9.0 & 8.5 & 8.0 & 7.5 & 7.0 & 6.5 & 6.0 & 5.5 & 5.0 & 4.5 & 4.0\end{array}$

Figure 3 Comparison of ${ }^{1} \mathrm{H}$ NMR in DMSO- $d_{6}$ for $\mathrm{OPP}(2)-\mathrm{OH}$ and OPP (2)-- (collected at $25^{\circ} \mathrm{C}$ and $60{ }^{\circ} \mathrm{C}, \sim 10 \mathrm{mmol} / \mathrm{L}$ ).

reflecting the enhanced quinoid character of the structure. The positive bond-length alternation value calculated with crystal-structure data for $\mathbf{O P P}(\mathbf{1})-\mathbf{0}^{-}$suggests a predominantly quinoid-type structure. ${ }^{38}$ In contrast, the small negative value calculated for $\left[\mathbf{O P P}(2)-\mathbf{O}^{-}\right]_{2} \cdot \mathbf{H C l}$ points to moderately zwitterionic character (Table S1, SI), likely due to the partial protonation.

\section{UV-vis Absorbance Spectroscopy}

UV-vis data were collected for the $\mathbf{O P P}(\boldsymbol{n})-\mathbf{O H}$ and $\mathbf{O P P}$

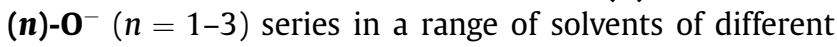
polarity (Figures 5-8). The solvent polarity scale was adopted from Reichardt's work. ${ }^{3}$ Absorbance maxima are provided in Table 1, as well as comparison with literature values ${ }^{14}$ for $\mathbf{O P P}(\mathbf{1})-\mathbf{0}^{-}$. Solvent choice was limited by solubility of the compounds, with lower polarity solvents such as chloroform or petroleum spirits not forming stable solutions of sufficient
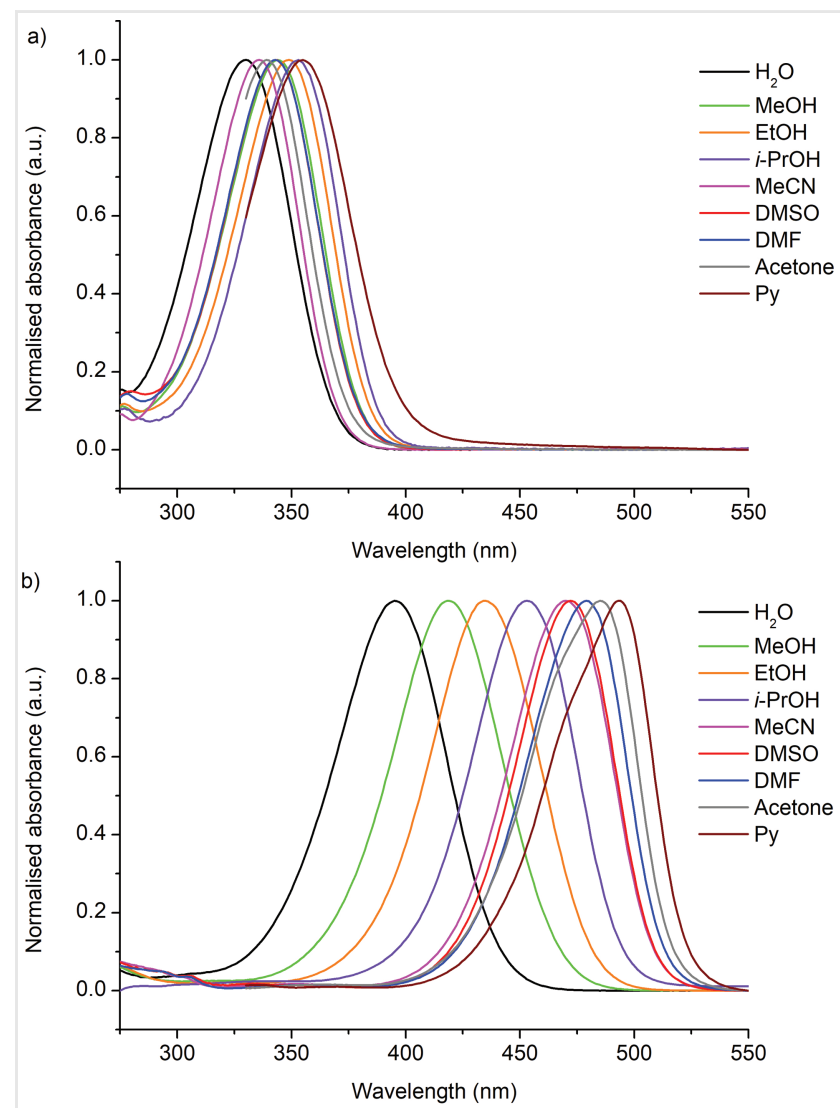

Figure 5 UV-vis absorbance spectra of OPP(1)-OH (a) and OPP(1)-O (b) in solvents of different polarity.

concentration. As was reported previously, ${ }^{9}$ deprotonated species exist in protic solvents only for a short time, and undergo fast protonation. For this reason, these solutions should be prepared directly before the measurements, and stabilized with an excess of base ( $>20$ equiv).

Absorbance profiles for the protonated compounds OPP (n)-OH $(n=1,2)$ showed one band, whose position did not uniformly shift in correlation with the solvent polarity (Figures 5a and 6a; Table 1). Upon deprotonation, a

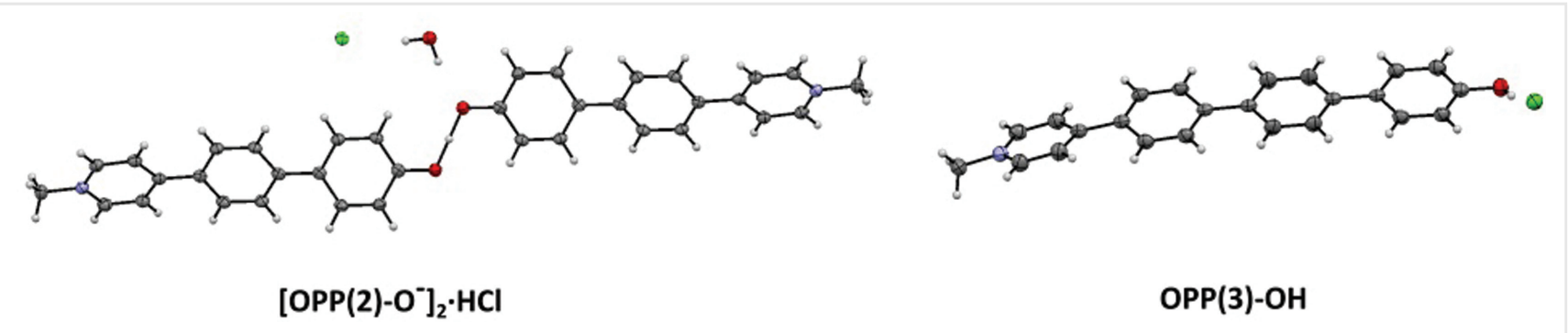

Figure 4 Crystal structures of $\left[\mathrm{OPP}(2)-\mathrm{O}^{-}\right]_{2} \cdot \mathbf{H C l}$ and $\mathbf{O P P ( 3 ) - O H . 3 7 ~ T h e r m a l ~ e l l i p s o i d s ~ a r e ~ d r a w n ~ a t ~ t h e ~} 50 \%$ probability level. 

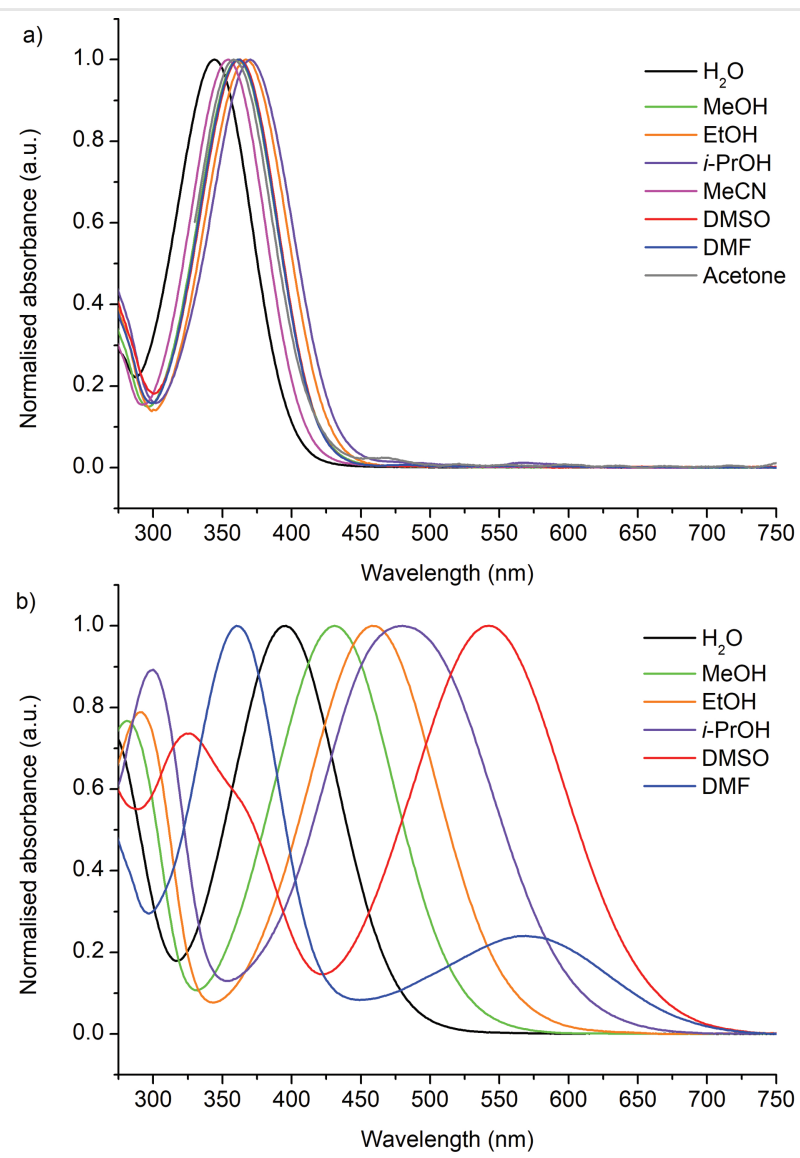

Figure 6 UV-vis absorbance spectra of $\mathrm{OPP}(2)-\mathrm{OH}$ (a) and $\mathrm{OPP}(2)-0$ (b) in solvents of different polarity.
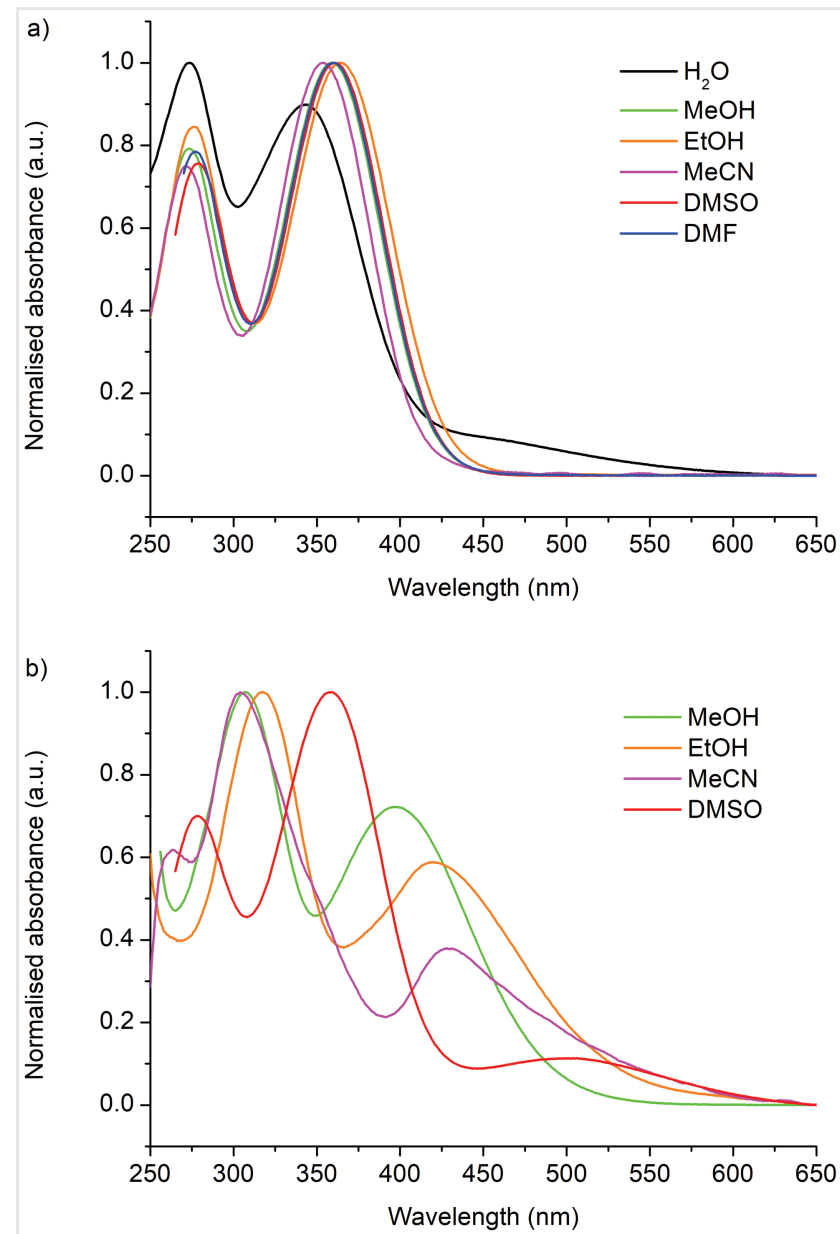

Figure 8 Absorbance spectra for OPP(3)-OH (a) and $\operatorname{OPP}(3)-0^{-}$(b) in solvents of different polarity.

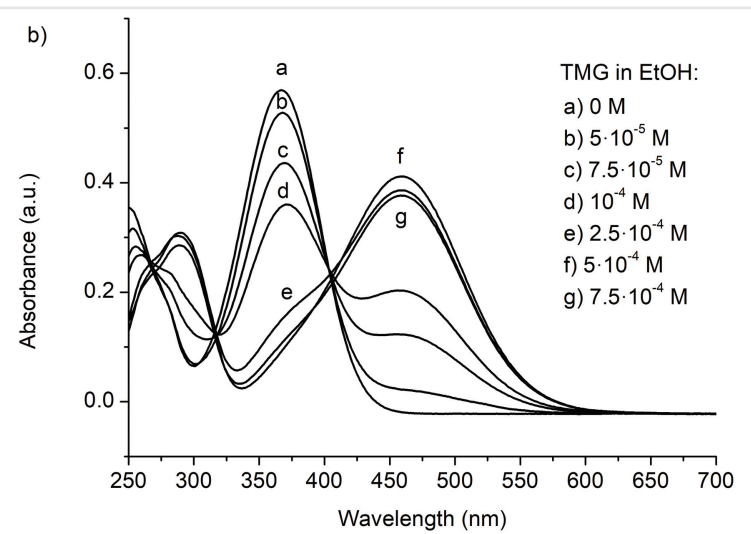

Figure 7 UV-vis absorbance spectra: a) comparison of OPP(2)-OH (solid lines) and OPP(2)-0- (dashed lines) in $\mathrm{H}_{2} \mathrm{O}$, $i$-PrOH, and DMSO; b) OPP(2)-OH $\left(3 \times 10^{-5} \mathrm{M}\right)$ in $\mathrm{EtOH}$ in the presence of various amounts of TMG.

bathochromic shift was observed in all solvents and there was a drastic effect of the medium polarity on position of the absorbance spectra of $\mathbf{O P P}(\boldsymbol{n})-\mathbf{0}^{-}(n=1,2)$ (Figures $5 \mathrm{~b}$ and 6b; Table 1). In the case of $\mathbf{O P P}(\mathbf{1})-\mathbf{O H}$, solutions in EtOH, DMF, and pyridine were stabilized with TFA $(\sim 10$ equiv) as the solutions prepared in pure solvent showed 
Table 1 Absorbance maxima obtained for $\operatorname{OPP}(n)-O H$ and $\operatorname{OPP}(n)-0^{-}$in solvents of different polarity

\begin{tabular}{|c|c|c|c|c|c|c|c|}
\hline \multirow[t]{2}{*}{$E_{\mathrm{T}}(30), \mathrm{kcal} \mathrm{mol}^{-13}$} & \multicolumn{7}{|c|}{$\lambda_{\max }$ abs, $\mathrm{nm}$} \\
\hline & Solvent & OPP(1)-OH & OPP(1)-- ${ }^{-}$(ref. 13) & OPP(2)-OH & OPP(2)-- ${ }^{-}$ & OPP(3)-OH & OPP(3)- $0^{-}$ \\
\hline 40.5 & Pyridine & 355 & $494(-)$ & $*$ & $*$ & $*$ & $*$ \\
\hline 42.2 & Acetone & 339 & 485 (479) & 358 & $*$ & $*$ & $*$ \\
\hline 43.2 & DMF & 343 & $479(-)$ & 362 & 360,563 & 277,360 & $*$ \\
\hline 45.1 & DMSO & 343 & $472(473)$ & 363 & 326,543 & 279,361 & $279,359,504$ \\
\hline 45.6 & $\mathrm{MeCN}$ & 336 & $470(472)$ & 354 & $*$ & 271,354 & $263,304,431$ \\
\hline 48.4 & $i-\mathrm{PrOH}$ & 353 & $453(457)$ & 370 & 300,480 & $*$ & $*$ \\
\hline 51.9 & $\mathrm{EtOH}$ & 349 & $434(-)$ & 367 & 290,458 & 277,365 & 318,420 \\
\hline 55.4 & $\mathrm{MeOH}$ & 344 & $419(418)$ & 361 & 281,431 & 273,359 & 307,397 \\
\hline 63.1 & $\mathrm{H}_{2} \mathrm{O}$ & 330 & 395 (394) & 344 & 396 & 274,343 & $*$ \\
\hline
\end{tabular}

*Values not obtained due to low solubility.

the presence of the deprotonated form (Figure S1, SI). Comparing the shifts between $\mathbf{O P P}(\mathbf{1})-\mathbf{O H}$ and $\mathbf{O P P}(\mathbf{1})-\mathbf{0}^{-}$, there is a $64 \mathrm{~nm}$ difference in the highest polarity solvent (water), while in moderately polar acetonitrile the difference grows to $128 \mathrm{~nm}$, reaching the largest bathochromic shift of $139 \mathrm{~nm}$ in the least polar solvent studied, pyridine.

The simplest zwitterionic compound obtained in this work, the $N$-methylpyridinium phenolate, $\mathbf{O P P}(\mathbf{1})-\mathbf{0}^{-}$, was thoroughly studied in order to reproduce the spectroscopic characteristics reported by Diemer et al. ${ }^{14}$ (Figure $5 \mathrm{~b}$ ). It was mentioned that the basicity of the analyzed solution played an important role in obtaining reliable data, though the nature of the base used was not specified. Thus, several bases were explored - $\mathrm{NaOH}$ (added as an aqueous solution), $\mathrm{NaH}, t$-BuOK, and 1,1,3,3-tetramethylguanidine (TMG). Spectra acquired with the addition of the aqueous solution of $\mathrm{NaOH}$ were 15-20 nm blueshifted compared with the literature values. ${ }^{14}$ It was possible that the addition of even small amounts of water considerably affected the solvation shell of the molecules in organic solvents. Usage of $\mathrm{NaH}$ and $t$-BuOK could not provide a full set of data, as these strong bases reacted with some solvents. Ultimately, we opted for the use of TMG ${ }^{40}$ for stabilization of all $\mathbf{O P P}(\boldsymbol{n})-\mathbf{O}^{-}$ species in the measured solutions, as it is a strong base which is fully miscible with water and most organic solvents. The maximum absorbance wavelengths derived for $\mathbf{O P P}(\mathbf{1})-\mathbf{0}^{-}$solutions with the addition of TMG are in good agreement with the reported values ${ }^{14}: 419$ and $418 \mathrm{~nm}$ in $\mathrm{MeOH}, 470$ and $472 \mathrm{~nm}$ in $\mathrm{MeCN}$, and 485 and $479 \mathrm{~nm}$ in acetone (Table 1 ).

Focusing on the absorbance spectra of $\mathbf{O P P}(\mathbf{1})-\mathbf{O}^{-}$in different solvents, a smooth bathochromic shift was observed with the decrease of the solvent polarity. The maximum absorbance wavelength changed from $395 \mathrm{~nm}$ for water to $494 \mathrm{~nm}$ for pyridine (Figure $5 \mathrm{~b}$, Table 1 ), thus demonstrating almost a $100 \mathrm{~nm}$ shift towards longer wavelengths and negative solvatochromic behavior.

UV-vis spectra for $\mathbf{O P P}(2)-\mathbf{O H}$ and $\mathbf{O P P}(2)-\mathbf{0}^{-}$are shown in Figure 6a and Figure 6b). Deprotonation induces a spectral shift towards longer wavelengths with a change of $52 \mathrm{~nm}$ for water, $110 \mathrm{~nm}$ for $i-\mathrm{PrOH}$, and a particularly pronounced value of $180 \mathrm{~nm}$ for DMSO (Figure 7a). Study of OPP(2)-0 $\mathbf{0}^{-}$behavior in solution reveals strong negative solvatochromism as the lowest energy transition is redshifted by $167 \mathrm{~nm}$ moving from highly polar water to comparatively lower polarity DMF (Figure 6b). This shift is almost twice that measured for $\mathbf{O P P}(\mathbf{1})-\mathbf{0}^{-}(84 \mathrm{~nm})$. Also, in contrast to $\mathbf{O P P}(\mathbf{1})-\mathbf{0}^{-}$, the absorbance profiles of $\mathbf{O P P}(\mathbf{2})-$ $\mathbf{0}^{-}$show at least two distinct maxima. Uniquely, in DMF solution, the most redshifted absorbance feature was no longer the most intense transition.

An additional study was carried out to track spectral changes between $\mathbf{O P P}(2)-\mathbf{O H}$ and $\mathbf{O P P}(2)-\mathbf{0}^{-}$. UV-vis spectra were acquired for the ethanol solutions of the protonated form OPP(2)-OH with a varying concentration of TMG (Figure 7b). The band at $367 \mathrm{~nm}$ gradually decreased and then disappeared completely while new bands at 290 and $458 \mathrm{~nm}$ arose upon increasing the TMG content in the solution, with isosbestic points visible around 316 and $406 \mathrm{~nm}$. This observation confirms that the former band at $367 \mathrm{~nm}$ originates from the protonated species $\mathbf{O P P}(\mathbf{2})-\mathbf{O H}$ and the latter redshifted one at $458 \mathrm{~nm}$ from the deprotonated ones of $\mathbf{O P P}(2)-\mathbf{0}^{-}$.

The absorbance spectra of $\mathbf{O P P}(3)-\mathbf{O H}$ and $\mathbf{O P P}(3)-\mathbf{0}^{-}$, containing two phenylene spacers, are shown in Figure 8a and Figure $8 \mathrm{~b}$, and the band positions are summarized in Table 1. The effect of solvents on the photophysical properties of these species was quite different from the shorter molecules. The absorbance profile for $\mathbf{O P P}(\mathbf{3})-\mathbf{O H}$ composed of two absorbance maxima, indicating two possible transitions in the measured wavelength range. Upon deprotonation, changes in spectral shapes and band 
positions were not consistent with polarity medium variations. One possible explanation is that the increased number of slightly twisted phenylene spacers hinders electron delocalization between the donor and acceptor ends, nearing the effective conjugation length for the system in solution. Interestingly, in most cases, the absorbance maximum for $\mathbf{O P P}(3)-\mathbf{O}^{-}$in the visible region was situated at shorter

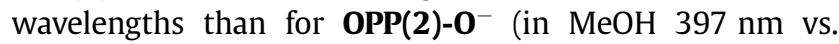
$432 \mathrm{~nm}$ ). It has been previously observed that the redshift in extended donor-acceptor OPPs is often saturated for biphenyl or terphenyl chains. ${ }^{41}$ Furthermore, the low solubility of the extended OPPs meant that aggregation effects could become important. Rod-like zwitterionic compounds are prone to forming head-tail dimers even in dilute solution. ${ }^{42}$ This could suppress solvatochromic variations, especially in lower polarity solvents which would have difficulty breaking apart the ionic pairs. However, dilution experiments (Figure S5, SI) suggested that this was not a major factor for $\mathbf{O P P}(\mathbf{3})-\mathbf{0}^{-}$in DMSO.

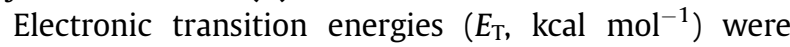
estimated for $\mathbf{O P P}(\boldsymbol{n})-\mathbf{O}^{-}$using the most redshifted absorbance maxima $\left(E_{\mathrm{T}}=28591 / \lambda_{\max }\right){ }^{3}$ Figure 9 shows the dependence of the transition energies on the polarity of the solvent for $\mathbf{O P P}(\boldsymbol{n})-\mathbf{O}^{-}$and Betaine 30. Data points were interpolated with the best linear fit, and the fitting parameters derived (Table S8, SI). Thus, among the studied examples, the slope for $\mathbf{O P P}(\mathbf{2})-\mathbf{0}^{-}(1.09 \pm 0.10)$ is equal to that for Betaine $\mathbf{3 0}$ (unity, by definition) within the error margin, suggesting that the dyes are comparably solvatochromic within the explored polarity range. This is noteworthy, as Betaine $\mathbf{3 0}$ is among the most solvatochromic organic dyes known. ${ }^{13}$ Like Betaine 30, OPP(2)-- ${ }^{-}$can be used as a polarity indicator.

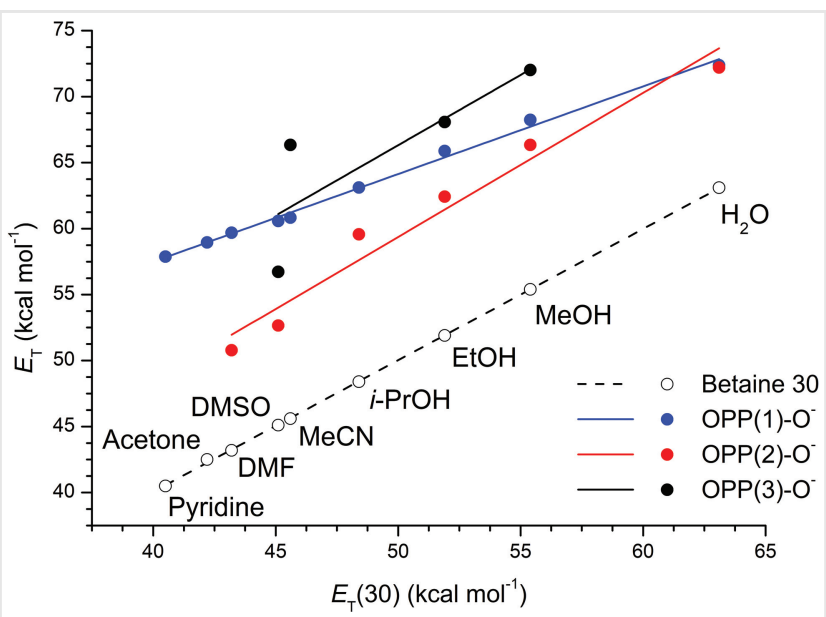

Figure 9 Transition energies of Betaine 30 and $\operatorname{OPP}(n)-0^{-}$versus the empirical parameter of polarity $E_{\mathrm{T}}(30)$.
The negative solvatochromic behavior of $\mathbf{O P P}(\mathbf{2})-\mathbf{0}^{-}$may be diminished in low polarity solvents (hydrocarbons, chlorinated solvents, etc.) as the system approaches a possible solvatochromic reversal region (similar to $\mathbf{B M}$ ). ${ }^{12}$ However, due to solubility limitations for $\mathbf{O P P}(\mathbf{2})-\mathbf{0}^{-}$, this cannot be easily verified.

\section{Theoretical Studies}

Several theoretical studies have been reported for OPP (1)-0 ${ }^{-}$as a model compound. ${ }^{43-45}$ However, the comparison of calculated structural and spectroscopic characteristics with experimental data is complicated by their strongly solvent-dependent nature. Therefore, solvation effects should be taken into consideration when performing molecular simulations. ${ }^{46,47}$ The negative solvatochromic behavior of $\mathbf{O P P}(\mathbf{1})-\mathbf{0}^{-}$has been comprehensively investigated with calculations in solvents of different polarity by implementing various solvation models using density functional theory (DFT) and time-dependent DFT (TD-DFT) methods, ${ }^{48}$ showing qualitative agreement with experimental results. Based on these findings, we carried out calculations for $\mathbf{O P P}(\boldsymbol{n})-\mathbf{0}^{-} \quad(n=1-3)$. Using the GAUSSIAN16 software suite, ${ }^{49}$ the ground-state geometry was optimized using the M06-2X functional and 6-31 + G $(d, p)$ basis set, while TD-DFT calculations were performed at the CAM-B3LYP/6-31 + G** level of theory. To complement the calculations performed under vacuum, implicit solvation was performed using a polarizable continuum model for $\mathrm{H}_{2} \mathrm{O} \quad(\varepsilon=78.39)$, DMSO $(\varepsilon=46.70)$, and acetone $(\varepsilon=20.70)$ included in both geometry optimization and energy calculations. The results obtained are given in Table S10 (SI). Figure 10a shows optimized geometries and frontier molecular orbitals of $\mathbf{O P P}(\boldsymbol{n})-\mathbf{0}^{-}(n=1-3)$ under vacuum. It should be noted that the structures were planar and HOMOs and LUMOs were delocalized throughout the chain even upon moving to extended analogues.

Meanwhile, calculations with implicit solvation resulted in geometric and electronic differences. The optimized geometries of $\mathbf{O P P}(\mathbf{2})-\mathbf{0}^{-}$and $\mathbf{O P P}(\mathbf{3})-\mathbf{0}^{-}$were no longer fully planar, with a small amount of twisting present between the rings. Figure 10b compares the HOMOs and LUMOs for OPPs in vacuum and aqueous medium. In the case of $\mathbf{O P P}(\mathbf{1})-\mathbf{O}^{-}$, the HOMO and LUMO distribution in water stayed the same as in the vacuum, while the energy levels were slightly lowered.

Considering $\mathbf{O P P}(\mathbf{2})-\mathbf{0}^{-}$, it was clearly seen that solvation triggered a spatial separation of the orbitals; as expected, the HOMO concentrated around the donor phenolate group while the LUMO moved towards the acceptor pyridinium unit, with small amounts of both orbitals still overlapping on the phenylene spacer. The trend 
a)

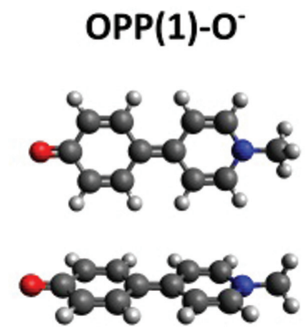

\begin{tabular}{|c|c|c|}
\hline $\begin{array}{l}\text { HOMO-2 } \\
\text { Q8y } \\
-8.463 \mathrm{eV}\end{array}$ & $\begin{array}{l}\text { HOMO-1 } \\
\text { serest } \\
-7.524 \mathrm{eV}\end{array}$ & $\begin{array}{l}\text { HOMO } \\
\text { Pateq } \\
-6.154 \mathrm{eV}\end{array}$ \\
\hline LUMO & LUMO+1 & LUMO+2 \\
\hline$d$ & oft & \\
\hline$-1.119 \mathrm{eV}$ & $-0.07 \mathrm{eV}$ & $0.096 \mathrm{eV}$ \\
\hline
\end{tabular}

b)

$$
\text { OPP(1)-0- }
$$

HOMO LUMO

Vacuum

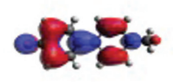

$-6.154 \mathrm{eV}$

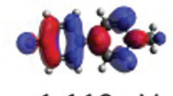

$\mathrm{H}_{2} \mathrm{O}$

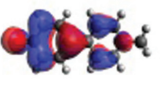

$-6.412 \mathrm{eV}$
$-1.119 \mathrm{eV}$

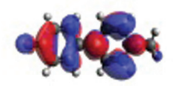

$-1.145 \mathrm{eV}$
OPP(2)-0

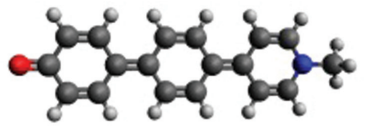

-gedpedpod

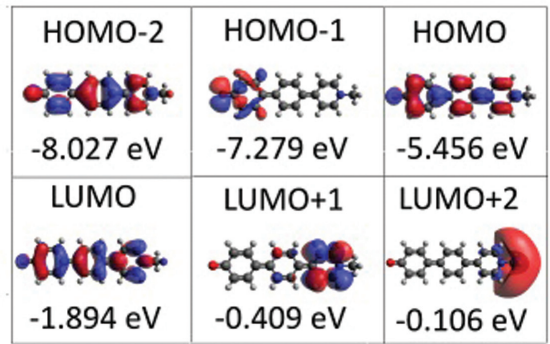

OPP(2)- $0^{-}$

HOMO

LUMO

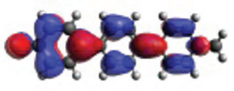

$-5.456 \mathrm{eV}$

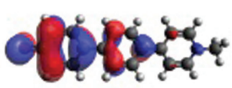

$-5.960 \mathrm{eV}$
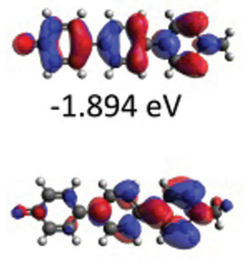

$-1.592 \mathrm{eV}$
OPP(3)-0
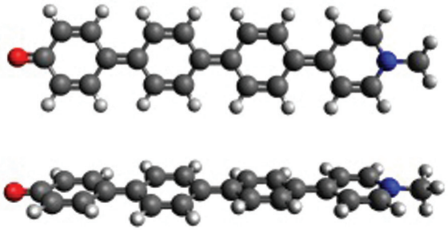

Figure 10 a) Optimized geometries and frontier molecular orbitals of $\mathrm{OPP}(n)-\mathbf{O}^{-}(n=1-3)$ in vacuum, b) HOMO and LUMO of $\mathrm{OPP}_{(n)-0^{-}}(n=1-3)$ in vacuum and $\mathrm{H}_{2} \mathrm{O}$.

towards separation of the orbitals continued for the quateraryl structure $\mathbf{O P P}(\mathbf{3})-\mathbf{0}^{-}$, where now the HOMO and LUMO no longer overlapped on the $\pi$-conjugated bridge. These calculations suggest that even modestly sized p-phenylene bridges can greatly hinder electron delocalization between the donor and acceptor ends in zwitterionic OPPs. In general, for $\mathbf{O P P}(2)-\mathbf{0}^{-}$and $\mathbf{O P P}(3)-\mathbf{0}^{-}$in $\mathrm{H}_{2} \mathrm{O}$, DMSO, or acetone, HOMO energies were lowered, while LUMO energies were raised compared with the values in vacuum. It is also worth noting the sharp increase of the ground-state dipole moments upon implicit solvation, in all cases roughly doubling relative to the vacuum calculations (Table S10, SI).

\section{Conclusions}

Zwitterionic OPPs with a donor phenolate group and an acceptor pyridinium moiety separated by one and two $p$-phenylene units were synthesized by the linear iterative coupling method using aryl nonaflates as effective coupling reagents, thus producing teraryl and quateraryl systems with good yields. For the studied $\mathbf{O P P}(\boldsymbol{n})-\mathbf{O H}$ and $\mathbf{O P P}(\boldsymbol{n})-\mathbf{0}^{-}$systems $(\boldsymbol{n}=1-3)$, a bathochromic shift occurred in absorbance spectra upon deprotonation. Also for deprotonated species, a redshift of the absorbance maxima was observed with decreased solvent polarity. The introduction of a $p$-phenylene spacer between the phenolate and pyridinium moieties in $\mathbf{O P P}(\mathbf{2})-\mathbf{0}^{-}$caused the molecule to display more extreme solvatochromic behavior when compared to OPP(1)- $\mathbf{O}^{-}$, increasing the solvatochromic shift from 84 to $167 \mathrm{~nm}$ while moving from water to DMF.

The magnitude of this shift is close to the strongly solvatochromic Betaine 30. In contrast, for the elongated system $\mathbf{O P P}(3)-\mathbf{O}^{-}$, the absorbance spectrum blueshifted compared to the shorter molecules.

Based on the data obtained, further extension of the chain $(n \geq 4)$ is unlikely to produce compounds with more redshifted absorbance in solution, as the HOMO and LUMO are expected to become more localized at the ends of the molecule, increasing their energetic separation. This can be taken as a measure of the degree of electron 
delocalization permitted through $p$-phenylene bridges. A fuller experimental investigation of longer zwitterions would require the preparation of $p$-phenylene spacers containing solubilizing groups, such as alkyl substituents. However, these modifications must be performed in such a way to avoid excessive electronic influences on the molecule, and to not induce further dihedral twisting of the $p$-phenylene rings.

\section{Experimental Section}

Commercial reagents were purchased from SigmaAldrich, AK Scientific, Matrix Scientific, Boron Molecular, Ajax Finechem, Univar, and Labchem, and were used as delivered. Commercially available NfF was stirred with $\mathrm{K}_{2} \mathrm{HPO}_{4} / \mathrm{K}_{3} \mathrm{PO}_{4}(1: 1, \mathrm{pH}=12-13)$ concentrated aqueous buffer for $96 \mathrm{~h}$, filtered, and distilled over $\mathrm{P}_{2} \mathrm{O}_{5}$ to remove perfluorosulfolane. $^{50}$ Anhydrous dichloromethane was obtained from alumina-packed drying columns, ${ }^{51}$ and anhydrous DMF and $\mathrm{Et}_{3} \mathrm{~N}$ were obtained by drying over activated molecular sieves. Standard Schlenk techniques were used for air-sensitive reactions. For oxygen-sensitive reactions, solvents were sparged with nitrogen gas for 30 min prior to addition, and the systems were closed with a rubber septum and maintained under positive nitrogen pressure. Purification via flash column chromatography was performed with Merck-Millipore silica gel (Kieselgel 60, 40-63 $\mu \mathrm{m}, 230-400$ mesh). Thin-layer chromatography was performed on Merck-Millipore Silica gel 60G $\mathrm{F}_{254}$ glass plates, and spots were revealed under 254 and $365 \mathrm{~nm}$ light from a mercury lamp.

${ }^{1} \mathrm{H}$ NMR (400, 500, and $600 \mathrm{MHz}$ ) and ${ }^{13} \mathrm{C}$ NMR (101, $126,151 \mathrm{MHz}$ ) spectra were registered on $400 \mathrm{MHz}$ Agilent, $500 \mathrm{MHz}$ Agilent, or $600 \mathrm{MHz}$ Varian spectrometers. ${ }^{19} \mathrm{~F}$ NMR $(470 \mathrm{MHz}$ ) spectra were obtained on a $500 \mathrm{MHz}$ Agilent spectrometer. ${ }^{1} \mathrm{H}$ NMR and ${ }^{13} \mathrm{C}$ NMR signals were referenced to $\mathrm{CDCl}_{3}, \mathrm{D}_{2} \mathrm{O}, \mathrm{CD}_{3} \mathrm{OD},\left(\mathrm{CD}_{3}\right)_{2} \mathrm{CO}$, or DMSO- $d_{6}$ solvent peaks. ${ }^{19} \mathrm{~F}$ NMR signals were referenced to an external standard of hexafluorobenzene in $\mathrm{CDCl}_{3}$ (-164.9 ppm). NMR spectroscopy solutions containing $\mathrm{NaOD}$ (typically ca. $1 \mathrm{M}$ ) were prepared by slowly dissolving $\mathrm{NaH}$ in a small amount of the desired solvent under an inert atmosphere, prior to addition of compound.

Mass spectra were obtained on an Agilent ESI-TOF-MS spectrometer operating in positive mode from methanolacetonitrile solutions containing formic acid as a proton source.

UV-vis absorbance spectra were obtained with an Agilent Cary UV-vis Compact Peltier UV-visible spectrometer. For UV-vis measurements solid samples were dissolved in the desired solvent and diluted as necessary $\left(\sim 10^{-5} \mathrm{~mol} / \mathrm{L}\right)$; zwitterionic species were maintained in the solution by addition of TMG ( $>20$ equiv).
Infrared absorption spectra were obtained with a Perkin-Elmer SpectrumOne ATR FT-IR spectrometer in the region of 650 to $4000 \mathrm{~cm}^{-1}$.

$\mathrm{X}$-ray diffraction intensity data were collected on the MX1 beamline at the Australian Synchrotron. ${ }^{52}$ The structure was solved by direct methods and difference Fourier synthesis. ${ }^{53}$ Thermal ellipsoid plots were generated using the program Mercury integrated within the WINGX suite of programs. ${ }^{54,55}$

\section{Procedures}

4-(Pyridin-4-yl)phenol (3) ${ }^{14}$ : In a $200 \mathrm{~mL}$ Schlenk tube with a magnetic stirrer were added $2.6 \mathrm{~g}$ (15 mmol, 1.0 equiv)

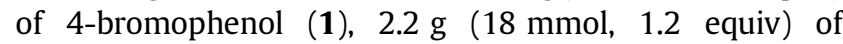
4-pyridinylboronic acid (2), $343 \mathrm{mg}$ (0.4 mmol, $2.5 \mathrm{~mol} \%)$ of tris(dibenzylideneacetone)dipalladium $(0) \quad\left(\mathrm{Pd}_{2} \mathrm{dba}_{3}\right)$, $331 \mathrm{mg}$ (0.9 mmol, $6.0 \mathrm{~mol} \%$ ) of tricyclohexylphosphonium

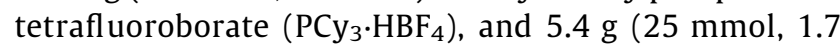
equiv) of $\mathrm{K}_{3} \mathrm{PO}_{4}$. After vacuum/nitrogen cycles, $40 \mathrm{~mL}$ of dioxane and $20 \mathrm{~mL}$ of distilled water $(2 / 1, \mathrm{v} / \mathrm{v})$ sparged with nitrogen were cannulated. The reaction mixture was stirred at $100{ }^{\circ} \mathrm{C}$ for $16 \mathrm{~h}$. The solvents were evaporated from the reaction mixture and the rest was transferred to a separatory funnel with chloroform and water. Excess of $5 \mathrm{~mol} / \mathrm{L} \mathrm{HCl}$ (aq.) was added until the aqueous layer had $\mathrm{pH}=0$ and precipitate dissolved completely. The mixture was washed with $3 \times 150 \mathrm{~mL}$ of chloroform and the organic layer was discarded. The aqueous layer was transferred to a larger beaker with a stirrer bar and an aqueous solution of $\mathrm{KHCO}_{3}$ (sat.) was slowly added until $\mathrm{pH}=7$. A large amount of white solid was formed and then filtered. The product was dried in a vacuum oven and collected as $2.1 \mathrm{~g}$ (82\%) of yellow solid.

$$
R_{\mathrm{f}}=0.5\left(\mathrm{CHCl}_{3}\right) \text {. }
$$

IR (solid, $\mathrm{cm}^{-1}$ ): 2575.7, 1598.9, 1583.4, 1518.9, 1489.5, $1446.2,1414.8,1382.8,1281.6,1246.4,1212.5,1173.1$, 1107.8, 1069.4, 1032.4, 1001.7, 894.1, 851.1, 808.7, 728.8, 665.5 .

${ }^{1} \mathrm{H}$ NMR (400 MHz, DMSO-d $)_{6}$ ): $9.83(\mathrm{~s}, 1 \mathrm{H}), 8.54$ (d, $\mathrm{J}=5.8 \mathrm{~Hz}, 2 \mathrm{H}), 7.66(\mathrm{~d}, \mathrm{~J}=8.6 \mathrm{~Hz}, 2 \mathrm{H}), 7.61(\mathrm{~d}, \mathrm{~J}=8.6 \mathrm{~Hz}$, $2 \mathrm{H}), 6.89(\mathrm{~d}, \mathrm{~J}=8.6 \mathrm{~Hz}, 2 \mathrm{H})$.

${ }^{13} \mathrm{C}$ NMR (101 MHz, CD $\left.\mathrm{OD}\right) \delta: 160.38,150.57,150.28$, 129.54, 129.33, 122.25, 117.07.

ESI-HRMS: $\quad m / z \quad[\mathrm{M}+\mathrm{H}]^{+}$calcd for $\mathrm{C}_{11} \mathrm{H}_{10} \mathrm{NO}$ : 172.07569; found: 172.07561 ( -0.5 ppm error).

4-(4-Hydroxyphenyl)-1-methylpyridinium iodide [OPP(1)-OH] ${ }^{14}$ : In a $100 \mathrm{~mL}$ Schlenk tube with a magnetic stirrer was added $785 \mathrm{mg}$ ( $4.6 \mathrm{mmol}, 1.0$ equiv) of 4 (pyridin-4-yl)phenol(3). After that $1.14 \mathrm{~mL}$ (18.3 mmol, 4.0 equiv) of methyl iodide (MeI) was transferred by a syringe and $70 \mathrm{~mL}$ of acetone was cannulated. The reaction mixture 
was stirred at $60{ }^{\circ} \mathrm{C}$ for $16 \mathrm{~h}$. The solvent was evaporated from the reaction mixture and the residue was washed with $\mathrm{Et}_{2} \mathrm{O}$ and EtOAc. The observed pale yellow solid was filtered giving $1.23 \mathrm{~g}(86 \%)$ of yield.

IR (film, $\mathrm{cm}^{-1}$ ): 3388.2, 3020.9, 1644.4, 1603.7, 1588.5, 1497.5, 1436.2, 1279.2, 1228.7, 1177.2, 827.1.

${ }^{1} \mathrm{H}$ NMR (400 MHz, CD $\left.{ }_{3} \mathrm{OD}\right) \delta: 8.72(\mathrm{~d}, J=6.9 \mathrm{~Hz}, 2 \mathrm{H})$, $8.27(\mathrm{~d}, J=6.7 \mathrm{~Hz}, 2 \mathrm{H}), 7.93(\mathrm{~d}, J=8.5 \mathrm{~Hz}, 2 \mathrm{H}), 7.00(\mathrm{~d}$, $J=8.4 \mathrm{~Hz}, 2 \mathrm{H}), 4.32(\mathrm{~s}, 3 \mathrm{H})$.

${ }^{13} \mathrm{C}$ NMR (101 MHz, CD $\left.\mathrm{OD}\right) \delta: 163.82,157.15,146.07$, 131.14, 125.40, 123.97, 117.91, 47.54.

ESI-HRMS: $m / z \quad\left[\mathrm{M}-\mathrm{I}^{-}\right]^{+}$calcd for $\mathrm{C}_{12} \mathrm{H}_{12} \mathrm{NO}$ : 186.09134; found: 186.09151 (+0.9 ppm error).

4-(1-Methylpyridinium-4-yl)phenolate [OPP(1)-
[OPle $\left.\mathbf{0}^{-}\right]^{14}$ : In a $20 \mathrm{~mL}$ microwave vial with a magnetic stirrer was added $200 \mathrm{mg}$ (0.64 mmol, 1.0 equiv) of 4-(4-hydroxyphenyl)-1-methylpyridinium iodide [OPP(1)-OH]. The vial was capped and $4 \mathrm{~mL}$ of $\mathrm{MeOH}$ was transferred followed by addition $0.8 \mathrm{~mL}$ ( $0.8 \mathrm{mmol}, 1.3$ equiv) of tetrabutylammonium hydroxide $\left(\mathrm{NBu}_{4} \mathrm{OH}, 1 \mathrm{~mol} / \mathrm{L}\right.$ solution in $\left.\mathrm{MeOH}\right)$. The reaction mixture was stirred at r.t. for $15 \mathrm{~min}$. The formed orange precipitate was filtered and washed with $\mathrm{DCM} / \mathrm{Et}_{2} \mathrm{O}$ $(1 / 1, \mathrm{v} / \mathrm{v})$. After drying in a vacuum oven overnight, $110 \mathrm{mg}$ (93\%) of orange solid was obtained.

IR (film, $\mathrm{cm}^{-1}$ ): 3445, 1643.9, 1568.4, 1486.8, 1307.2, 1202.3, 1168.7, 827.9, 686.5.

${ }^{1} \mathrm{H}$ NMR (600 MHz, DMSO- $\left.d_{6}\right) \delta: 8.48(\mathrm{~d}, \mathrm{~J}=7.0 \mathrm{~Hz}, 2$ $\mathrm{H}), 8.04(\mathrm{~d}, \mathrm{~J}=7.2 \mathrm{~Hz}, 2 \mathrm{H}), 7.80(\mathrm{~d}, \mathrm{~J}=9.0 \mathrm{~Hz}, 2 \mathrm{H}), 6.56(\mathrm{~d}$, $\mathrm{J}=9.0 \mathrm{~Hz}, 2 \mathrm{H}), 4.08(\mathrm{~s}, 3 \mathrm{H}) .{ }^{1} \mathrm{H}$ NMR $\left(600 \mathrm{MHz}, \mathrm{D}_{2} \mathrm{O}\right.$, NaOD) $\delta: ~ 7.80(d, J=6.7 \mathrm{~Hz}, 2 \mathrm{H}), 7.34(\mathrm{~d}, \mathrm{~J}=7.1 \mathrm{~Hz}, 2 \mathrm{H})$, 7.23 (d, J = 8.9 Hz, $2 \mathrm{H}$ ), 6.39 (d, J = 8.8 Hz, $2 \mathrm{H}$ ), 3.77 (s, 3 $\mathrm{H}) .{ }^{1} \mathrm{H}$ NMR (600 MHz, CD $\left.\mathrm{OD}, \mathrm{NaOD}\right) \delta: 8.33(\mathrm{~d}, \mathrm{~J}=6.9 \mathrm{~Hz}$, $2 \mathrm{H}), 7.92$ (d, J = 5.3 Hz, $2 \mathrm{H}), 7.70$ (d, J = 9.2 Hz, $2 \mathrm{H}), 6.61$ $(\mathrm{d}, \mathrm{J}=8.9 \mathrm{~Hz}, 2 \mathrm{H}), 4.13(\mathrm{~s}, 3 \mathrm{H})$.

${ }^{13} \mathrm{C}$ NMR (151 MHz, CD $\left.\mathrm{OD}, \mathrm{NaOD}\right) \delta: 177.18,156.71$, 144.27, 131.25, 121.91, 120.76, 117.56, 46.46 .

ESI-HRMS: $m / z \quad[\mathrm{M}+\mathrm{H}]^{+}$calcd for $\mathrm{C}_{12} \mathrm{H}_{12} \mathrm{NO}$ : 186.09134; found: 186.09147 ( +0.7 ppm error).

1-(Benzyloxy)-4-bromobenzene $\mathbf{( 4}^{56}$ : In a $100 \mathrm{~mL}$ round-bottom flask (RBF) with a magnetic stirrer were transferred $2.0 \mathrm{~g}$ ( $11.5 \mathrm{mmol}, 1.0$ equiv) of 4-bromophenol (1), $4.8 \mathrm{~g}$ (34.6 mmol, 3.0 equiv) of $\mathrm{K}_{2} \mathrm{CO}_{3}$, and $0.19 \mathrm{~g}$ (1.15 mmol, $10 \mathrm{~mol} \%$ ) of KI. The RBF was equipped with a condenser and $50 \mathrm{~mL}$ of acetone was cannulated. After that $1.46 \mathrm{~mL}$ (12.7 mmol, 1.1 equiv) of $\mathrm{BnCl}$ was transferred by a syringe. The reaction mixture was stirred at $60^{\circ} \mathrm{C}$ for $16 \mathrm{~h}$ and after completion transferred to a separatory funnel with $15 \mathrm{~mL}$ of EtOAc. The reaction mixture was washed with $5 \times 15 \mathrm{~mL}$ of water. The organic layer was dried with $\mathrm{MgSO}_{4}$ and filtered. The solvent was removed by rotary evaporation giving $3.1 \mathrm{~g}$ (98\%) of colorless oil, which was dried in a vacuum oven and used in the next step without any further purification.

$R_{\mathrm{f}}=0.24$ (petroleum spirits).
IR (film, $\mathrm{cm}^{-1}$ ): 3524.2, 3032.2, 1589.1, 1486.8, 1453.8, $1381.3,1285.5,1239.2,1171.2,1102.5,1072,1002.1,820.6$, 734.6, 696.8.

${ }^{1} \mathrm{H}$ NMR $\left(500 \mathrm{MHz}, \mathrm{CDCl}_{3}\right)$ \&: 7.48-7.35 (m, $\left.7 \mathrm{H}\right), 6.89(\mathrm{~d}$, $\mathrm{J}=8.6 \mathrm{~Hz}, 2 \mathrm{H}), 5.06(\mathrm{~s}, 2 \mathrm{H})$.

${ }^{13} \mathrm{C}$ NMR $\left(126 \mathrm{MHz}, \mathrm{CDCl}_{3}\right)$ \&: 157.90, 136.59, 132.36, 128.72, 128.19, 127.53, 116.75, 113.18, 70.24.

ESI-HRMS: $m / z$ [M] ${ }^{*+}$ calcd for $\mathrm{C}_{13} \mathrm{H}_{11} \mathrm{BrO}$ : 261.99878; found: 261.99839 (-1.5 ppm error).

4'-(Benzyloxy)-[1,1'-biphenyl]-4-ol (6) ${ }^{57}$ : In a $100 \mathrm{~mL}$ Schlenk tube with a magnetic stirrer were added $2.0 \mathrm{~g}$ (7.6 mmol, 1.0 equiv) of 1-(benzyloxy)-4-bromobenzene (4), $1.25 \mathrm{~g}$ (9.12 mmol, 1.2 equiv) of (4-hydroxyphenyl) boronic acid (5) , $34.8 \mathrm{mg}(0.04 \mathrm{mmol}, 0.5 \mathrm{~mol} \%)$ of $\mathrm{Pd}_{2} \mathrm{dba}_{3}$, $33.6 \mathrm{mg}$ (0.09 mmol, $1.2 \mathrm{~mol} \%)$ of $\mathrm{PCy}_{3} \cdot \mathrm{HBF}_{4}$, and $2.4 \mathrm{~g}$ (11.4 mmol, 1.5 equiv) of $\mathrm{K}_{3} \mathrm{PO}_{4}$. After vacuum/nitrogen cycles, $20 \mathrm{~mL}$ of dioxane and $10 \mathrm{~mL}$ of distilled water $(2 / 1$, $\mathrm{v} / \mathrm{v}$ ) sparged with nitrogen were cannulated. The reaction mixture was stirred at $100{ }^{\circ} \mathrm{C}$ for $16 \mathrm{~h}$. The solvents were evaporated from the reaction mixture and the rest was transferred to a separatory funnel with EtOAc and water. The mixture was washed with $2 \times 50 \mathrm{~mL}$ of $\mathrm{NH}_{4} \mathrm{Cl}$ (sat.) aqueous solution until $\mathrm{pH}=7$ and $2 \times 50 \mathrm{~mL}$ of water and the aqueous layer was discarded. The organic layer was collected, dried with $\mathrm{MgSO}_{4}$, and filtered. The solvent was removed by rotary evaporation and the crude product was filtered through a small silica gel plug using hot EtOAc. The solvent was removed under reduced pressure and the product was recrystallized from toluene. After filtration and drying in a vacuum oven, $1.56 \mathrm{~g}$ (70\%) of white solid was obtained.

$R_{\mathrm{f}}=0.22\left(\mathrm{CHCl}_{3}:\right.$ toluene $\left.2: 1\right)$.

IR (film, $\mathrm{cm}^{-1}$ ): 3438.1, 3048.3, 3035, 2907.7, 2866.2, $1610.5,1596.8,1500.1,1470,1454.1,1408.9,1375,1315$, $1302.5,1282.9,1263.6,1247.4,1192.1,1176.4,1134.6$, 1082.6, 1027.2, 1008.9, 918.7, 862.9, 837.8, 813, 746, 699.8.

${ }^{1} \mathrm{H}$ NMR (500 MHz, $\left.\left(\mathrm{CD}_{3}\right)_{2} \mathrm{CO}\right) \delta: 8.35(\mathrm{~s}, 1 \mathrm{H}), 7.52-7.48$ (m, $5 \mathrm{H}), 7.44(\mathrm{~d}, \mathrm{~J}=8.6 \mathrm{~Hz}, 2 \mathrm{H}), 7.40(\mathrm{t}, \mathrm{J}=7.7,7.1 \mathrm{~Hz}, 2$ $\mathrm{H}), 7.33(\mathrm{t}, \mathrm{J}=7.5 \mathrm{~Hz}, 1 \mathrm{H}), 7.06(\mathrm{~d}, \mathrm{~J}=8.8 \mathrm{~Hz}, 2 \mathrm{H}), 6.90$ (d, $\mathrm{J}=8.7 \mathrm{~Hz}, 2 \mathrm{H}), 5.15(\mathrm{~s}, 2 \mathrm{H})$.

${ }^{13} \mathrm{CNMR}\left(126 \mathrm{MHz},\left(\mathrm{CD}_{3}\right)_{2} \mathrm{CO}\right) \delta: 158.76,157.48,138.49$, $134.63,132.93,129.28,128.59,128.39,128.37,128.16$, 116.47, 115.98, 70.48 .

ESI-MS (positive mode): $m / z[\mathrm{M}]^{\bullet+}$ calcd for $\mathrm{C}_{19} \mathrm{H}_{16} \mathrm{O}_{2}$ : 276.11448; found: 276.11438 (-0.4 ppm error).

4'-(Benzyloxy)-[1,1'-biphenyl]-4-yl 1,1,2,2,3,3,4,4,4nonafluorobutane-1-sulfonate (7): In a $100 \mathrm{~mL}$ Schlenk tube with a magnetic stirrer was added $1.0 \mathrm{~g}(3.6 \mathrm{mmol}$, 1.0 equiv) of $4^{\prime}$-(benzyloxy)-[1,1'-biphenyl]-4-ol (6). After vacuum/nitrogen cycles, $30 \mathrm{~mL}$ of anhydrous DCM was cannulated and $0.75 \mathrm{~mL}$ (5.4 mmol, 1.5 equiv) of anhydrous $\mathrm{Et}_{3} \mathrm{~N}$ was transferred by a syringe. The reaction mixture was stirred and cooled to $0{ }^{\circ} \mathrm{C}$ followed by 
addition of $0.77 \mathrm{~mL}$ ( $4.3 \mathrm{mmol}, 1.2$ equiv) of NfF dropwise by a syringe. The reaction mixture was stirred at r.t. for $16 \mathrm{~h}$. After completion, the reaction mixture was diluted with an equal amount $(30 \mathrm{~mL})$ of petroleum spirits and filtered through a small silica gel plug using petroleum spirits:DCM 1:1 mixture. The solvents were removed under reduced pressure and the final product was obtained after drying in a vacuum oven as $1.97 \mathrm{~g}(98 \%)$ of white solid.

$R_{\mathrm{f}}=0.2$ (petroleum spirits:DCM 5:1).

IR (film, $\mathrm{cm}^{-1}$ ): 3038.8, 2897, 2859.2, 1610, 1597.1, $1571.1,1493,1468.5,1456.5,1432.4,1385.2,1354.4$, $1291.7,1244.6,1199.7,1140.1,1123.2,1106.2,1033.8$, 1016.4, 1002.1, 943.7, 890.1, 848.4, 837.7, 813.8, 766, 743.8, 732, 697.6, 674.6.

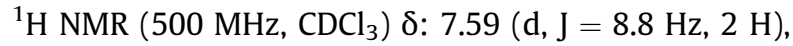
$7.49(\mathrm{~d}, \mathrm{~J}=8.8 \mathrm{~Hz}, 2 \mathrm{H}), 7.46(\mathrm{~d}, \mathrm{~J}=7.3 \mathrm{~Hz}, 2 \mathrm{H}), 7.41(\mathrm{t}$, $\mathrm{J}=7.6 \mathrm{~Hz}, 2 \mathrm{H}), 7.39-7.30(\mathrm{~m}, 3 \mathrm{H}), 7.07$ (d, J = 8.8 Hz, 2H), $5.12(\mathrm{~s}, 1 \mathrm{H})$.

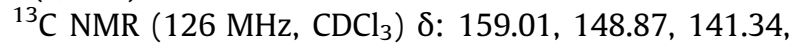
$136.86,132.12,128.79,128.45,128.42,128.23,127.62$, $121.73,115.46,70.23$.

${ }^{19} \mathrm{~F} \mathrm{NMR}\left(470 \mathrm{MHz}, \mathrm{CDCl}_{3}\right)$ \&: $-80.61,-108.92,-120.85$, -125.79 .

ESI-HRMS: $m / z[M]^{*+}$ calcd for $\mathrm{C}_{23} \mathrm{H}_{15} \mathrm{~F}_{9} \mathrm{O}_{4} \mathrm{~S}: 558.05418$; found: 558.05481 ( $+0.1 \mathrm{ppm}$ error).

4"-(Benzyloxy)-[1,1':4',1"-terphenyl]-4-ol (8): In a $100 \mathrm{~mL}$ Schlenk tube with a magnetic stirrer were added $1.0 \mathrm{~g}$ (1.7 mmol, 1.0 equiv) of 4'-(benzyloxy)-[1,1'-biphenyl]4-yl 1,1,2,2,3,3,4,4,4-nonafluorobutane-1-sulfonate (7), $1.3 \mathrm{~g}$ (2.1 mmol, 1.2 equiv) of (4-hydroxyphenyl)boronic acid (5), $7.8 \mathrm{mg}(8.5 \mu \mathrm{mol}, 0.5 \mathrm{~mol} \%)$ of $\mathrm{Pd}_{2} \mathrm{dba}_{3}, 7.5 \mathrm{mg}(20.4 \mu \mathrm{mol}$, $1.2 \mathrm{~mol} \%$ ) of $\mathrm{PCy}_{3} \cdot \mathrm{HBF}_{4}$, and $0.6 \mathrm{~g}$ ( $2.9 \mathrm{mmol}, 1.7$ equiv) of $\mathrm{K}_{3} \mathrm{PO}_{4}$. After vacuum/nitrogen cycles, $20 \mathrm{~mL}$ of dioxane and $10 \mathrm{~mL}$ of distilled water $(2 / 1, \mathrm{v} / \mathrm{v})$ sparged with nitrogen were cannulated. The reaction mixture was stirred at $100{ }^{\circ} \mathrm{C}$ for $16 \mathrm{~h}$. After completion, $10 \mathrm{~mL}$ of $\mathrm{MeOH}$ and $10 \mathrm{~mL}$ of water were added to the reaction mixture and the crude product was filtered and washed with $3 \times 20 \mathrm{~mL}$ of hot $\mathrm{CHCl}_{3}$ (to remove unreacted starting material) and $3 \times 20 \mathrm{~mL}$ of $\mathrm{MeOH}$ and water. After drying in a vacuum oven, $336 \mathrm{mg}$ (56\%) of gray solid was collected. As the product was poorly soluble in most organic solvents, it was used in the next step without any further purification.

IR (solid, $\mathrm{cm}^{-1}$ ): 3430.8, 3064.8, 3035.2, 2907.2, 2865.9, 1606.7, 1596.4, 1580.7, 1558.4, 1536.5, 1490.4, 1468.6, 1454.6, 1447.9, 1420, 1401.7, 1376.6, 1315.9, 1285, 1261.1, $1246.4,1181.1,1144.1,1110.4,1084.6,1036.1,1020.1$, 1007.9, 998.2, 918, 861.1, 829.7, 808.5, 755.4, 737.4, 713.2, 697.6, 678.3, 661.3.

${ }^{1} \mathrm{H}$ NMR (500 MHz, DMSO-d $\left.{ }_{6}\right) \delta: 9.57(\mathrm{~s}, 1 \mathrm{H}), 7.68-7.61$ (m, $6 \mathrm{H}), 7.52(\mathrm{~d}, \mathrm{~J}=8.6 \mathrm{~Hz}, 2 \mathrm{H}), 7.47(\mathrm{~d}, \mathrm{~J}=7.0 \mathrm{~Hz}, 2 \mathrm{H})$, $7.41(\mathrm{t}, \mathrm{J}=7.5 \mathrm{~Hz}, 2 \mathrm{H}), 7.34(\mathrm{t}, \mathrm{J}=7.3 \mathrm{~Hz}, 1 \mathrm{H}), 5.16(\mathrm{~s}, 2 \mathrm{H})$.
${ }^{13} \mathrm{C}$ NMR (126 MHz, DMSO- $\left.d_{6}\right) \delta: 157.90,157.16,138.51$, $137.64,137.08,132.30,130.35,128.44,127.82,127.64$, 127.53, 127.50, 126.50, 126.31, 115.75, 115.27, 69.24.

ESI-HRMS: $m / z[M]^{*+}$ calcd for $\mathrm{C}_{25} \mathrm{H}_{20} \mathrm{O}_{2}: 352.14578$; found: 352.14591 ( +0.4 ppm error).

4"-(Benzyloxy)-[1,1':4',1"-terphenyl]-4-yl

1,1,2,2,3,3,4,4,4-nona-fluorobutane-1-sulfonate (9): In a $100 \mathrm{~mL}$ Schlenk tube with a magnetic stirrer was added $200 \mathrm{mg}$ ( $0.57 \mathrm{mmol}, 1.0$ equiv) of $4^{\prime \prime}$-(benzyloxy)-[1,1':4',1"terphenyl]-4-ol (8). After vacuum/nitrogen cycles, $20 \mathrm{~mL}$ of anhydrous DMF was cannulated and $0.12 \mathrm{~mL}(0.85 \mathrm{mmol}$, 1.5 equiv) of anhydrous $\mathrm{Et}_{3} \mathrm{~N}$ was transferred by a syringe. The reaction mixture was stirred and cooled to $0{ }^{\circ} \mathrm{C}$ followed by addition of $0.12 \mathrm{~mL}(0.68 \mathrm{mmol}, 1.2$ equiv) of $\mathrm{NfF}$ dropwise by a syringe. After that, the reaction mixture was stirred at $60{ }^{\circ} \mathrm{C}$ for $16 \mathrm{~h}$. After completion, the reaction mixture was evaporated and filtered through a small silica gel plug using toluene:DCM $(1: 1, v / v)$ mixture. The solvents were removed under reduced pressure and the final product was obtained after drying in a vacuum oven as $340 \mathrm{mg}$ (94\%) of white solid.

$R_{\mathrm{f}}=0.96$ (toluene:DCM 1:1).

IR (film, $\mathrm{cm}^{-1}$ ): 1603.9, 1489.3, 1431.2, 1354.3, 1291.3, 1198, 1141.4, 1036.3, 1016, 885.8, 811.1, 776, 731.9, 695.4.

${ }^{1} \mathrm{H}$ NMR $\left(500 \mathrm{MHz}, \mathrm{CDCl}_{3}\right) \delta: 7.68(\mathrm{~d}, \mathrm{~J}=8.8 \mathrm{~Hz}, 2 \mathrm{H})$, $7.65(\mathrm{~d}, \mathrm{~J}=8.6 \mathrm{~Hz}, 2 \mathrm{H}), 7.61(\mathrm{~d}, \mathrm{~J}=8.5 \mathrm{~Hz}, 2 \mathrm{H}), 7.58(\mathrm{~d}$, $\mathrm{J}=8.7 \mathrm{~Hz}, 2 \mathrm{H}), 7.47(\mathrm{~d}, \mathrm{~J}=7.1 \mathrm{~Hz}, 2 \mathrm{H}), 7.41(\mathrm{t}, \mathrm{J}=7.4 \mathrm{~Hz}$, $2 \mathrm{H}), 7.38-7.33$ (m, $3 \mathrm{H}$ ), 7.08 (d, J = 8.7 Hz, $2 \mathrm{H}$ ), 5.13 (s, 2 $\mathrm{H})$.

${ }^{13} \mathrm{C}$ NMR (126 MHz, $\left.\mathrm{CDCl}_{3}\right)$ \&: 158.60, 149.11, 141.21, $140.50,137.50,136.86,133.05,128.65,128.10,128.05$, $127.51,127.49,127.22,121.68,115.24,70.10,29.72$.

${ }^{19} \mathrm{~F} \mathrm{NMR}\left(470 \mathrm{MHz}, \mathrm{CDCl}_{3}\right) \delta:-80.59,-108.86,-120.85$, -125.80 .

ESI-HRMS: $m / z$ [M] $]^{*+}$ calcd for $\mathrm{C}_{29} \mathrm{H}_{19} \mathrm{~F}_{9} \mathrm{O}_{4} \mathrm{~S}: 634.08549$; found: 634.08525 ( $-0.4 \mathrm{ppm}$ error).

4-(4'-(Benzyloxy)-[1,1'-biphenyl]-4-yl)pyridine (10): In a $100 \mathrm{~mL}$ Schlenk tube with a magnetic stirrer were added $2.5 \mathrm{~g}$ (4.4 mmol, 1.0 equiv) of 4'-(benzyloxy)-[1,1'-biphenyl]4-yl 1,1,2,2,3,3,4,4,4-nonafluorobutane-1-sulfonate (7), $0.66 \mathrm{~g}$ (5.3 mmol, 1.2 equiv) of 4-pyridinylboronic acid, $20.1 \mathrm{mg}$ (0.022 mmol, $0.5 \mathrm{~mol} \%)$ of $\mathrm{Pd}_{2} \mathrm{dba}_{3}, 19.4 \mathrm{mg}$ (0.053 mmol, $1.2 \mathrm{~mol} \%$ ) of $\mathrm{PCy}_{3} \cdot \mathrm{HBF}_{4}$, and $1.58 \mathrm{~g}$ ( $7.48 \mathrm{mmol}, 1.7$ equiv) of $\mathrm{K}_{3} \mathrm{PO}_{4}$. The tube was capped and after vacuum/nitrogen cycles, $50 \mathrm{~mL}$ of dioxane and $25 \mathrm{~mL}$ of distilled water $(2 / 1, v / v)$ sparged with nitrogen were cannulated. The reaction mixture was stirred at $100{ }^{\circ} \mathrm{C}$ for $16 \mathrm{~h}$. After completion, the crude product was filtered and washed with $3 \times 250 \mathrm{~mL}$ of $\mathrm{MeOH}$ and water. After that solid was dissolved in $\mathrm{CDCl}_{3}$ and loaded onto silica, then eluted through a silica gel plug using EtOAc:DCM $(1: 1, \mathrm{v} / \mathrm{v})$ mixture. The solvents were removed under reduced pressure and the final product was obtained after drying in a vacuum 
oven as $1.05 \mathrm{~g}$ (70\%) of white solid. The obtained compound is poorly soluble in most organic solvents.

$R_{\mathrm{f}}=0.36$ (EtOAc:DCM 1:1).

IR (film, $\mathrm{cm}^{-1}$ ): 3038, 2923.4, 2854.4, 1540.3, 1508, $1486.8,1460.6,1450.9,1409.3,1379.8,1290.3,1254.8$, 1230.7, 1210.6, 1181.9, 1117.6, 1045.9, 1028.4, 1000.3, 833.1, 805.1, 735.1, 696.1.

${ }^{1} \mathrm{H}$ NMR $\left(500 \mathrm{MHz}, \mathrm{CDCl}_{3}\right) \delta: 8.67(\mathrm{~d}, \mathrm{~J}=6.1 \mathrm{~Hz}, 2 \mathrm{H})$, $7.71(\mathrm{~d}, \mathrm{~J}=8.5 \mathrm{~Hz}, 2 \mathrm{H}), 7.68(\mathrm{~d}, \mathrm{~J}=8.4 \mathrm{~Hz}, 2 \mathrm{H}), 7.58(\mathrm{~d}$, $\mathrm{J}=8.8 \mathrm{~Hz}, 2 \mathrm{H}), 7.55(\mathrm{~d}, \mathrm{~J}=6.0 \mathrm{~Hz}, 2 \mathrm{H}), 7.47(\mathrm{~d}, \mathrm{~J}=7.2 \mathrm{~Hz}$, $2 \mathrm{H}), 7.41(\mathrm{t}, \mathrm{J}=7.4 \mathrm{~Hz}, 2 \mathrm{H}), 7.35(\mathrm{t}, \mathrm{J}=7.2 \mathrm{~Hz}, 1 \mathrm{H}), 7.08(\mathrm{~d}$, $\mathrm{J}=8.6 \mathrm{~Hz}, 2 \mathrm{H}), 5.13(\mathrm{~s}, 2 \mathrm{H})$.

${ }^{13} \mathrm{C}$ NMR (151 MHz, $\left.\mathrm{CDCl}_{3}\right)$ \&: 158.92, 149.98, 148.44, $141.86,136.99,136.22,133.01,128.79,128.30,128.20$, 127.62, 127.52, 127.50, 121.63, 115.46, 70.28.

ESI-HRMS: $\quad m / z \quad[\mathrm{M}+\mathrm{H}]^{+}$calcd for $\mathrm{C}_{24} \mathrm{H}_{20} \mathrm{NO}$ : 338.15394; found: 338.15472 (+0.2 ppm error).

4-(4"-(Benzyloxy)-[1,1':4',1"-terphenyl]-4-yl)pyridine (11): In $3 \times 20 \mathrm{~mL}$ microwave vials with a magnetic stirrer each were added $500 \mathrm{mg}(0.79 \mathrm{mmol}, 1.0$ equiv $)$ of 4"-(benzyloxy)-[1,1':4',1"-terphenyl]-4-yl 1,1,2,2,3,3,4,4,4nonafluorobutane-1-sulfonate (9), $194 \mathrm{mg}$ (1.6 mmol, 2.0 equiv) of 4-pyridinylboronic acid, $18.0 \mathrm{mg}$ (0.02 mmol, $2.5 \mathrm{~mol} \%)$ of $\mathrm{Pd}_{2} \mathrm{dba}_{3}, 17.4 \mathrm{mg}$ of $\mathrm{PCy}_{3} \cdot \mathrm{HBF}_{4}(0.05 \mathrm{mmol}$, $6.0 \mathrm{~mol} \%)$, and $284.3 \mathrm{mg}\left(1.34 \mathrm{mmol}, 1.7\right.$ equiv) of $\mathrm{K}_{3} \mathrm{PO}_{4}$. The vial was capped and after vacuum/nitrogen cycles, $12.5 \mathrm{~mL}$ of THF and $1.25 \mathrm{~mL}$ of distilled water $(10 / 1, \mathrm{v} / \mathrm{v})$ sparged with nitrogen were cannulated. The reaction mixture was stirred at $100^{\circ} \mathrm{C}$ for $48 \mathrm{~h}$. After completion, the reaction mixtures were joined and the crude product was filtered and washed with $3 \times 60 \mathrm{~mL}$ of $\mathrm{MeOH}$ and water. After that, the crude product was loaded onto silica and purified by Soxhlet extraction with hot $\mathrm{CHCl}_{3}$. After 2 days, white solid crashed out in the collection flask. The formed product was filtered and washed with $\mathrm{CHCl}_{3}$. After drying under high vacuum overnight, $585 \mathrm{mg}$ (60\%) of white solid was obtained. The compound is almost insoluble in most organic solvents.

IR (solid, $\mathrm{cm}^{-1}$ ): 3059.7, 3037.2, 2883.8, 2855.5, 1591, 1582 , 1557.7, 1539.5, 1497.2, 1483.8, 1459.7, 1451.4, $1415.3,1403.7,1377.1,1338.5,1317.1,1289.4,1267.6$, $1249.2,1231.8,1220.5,1205,1178.1,1153.4,1116.2$, 1079.1, 1044.8, 1026.8, 999.9, 990.4, 909.5, 852.4, 824.8, 802.6, 730.5, 696.6, 667.6.

${ }^{1} \mathrm{H}$ NMR $\left(600 \mathrm{MHz}, \mathrm{CDCl}_{3}, 60{ }^{\circ} \mathrm{C}\right) \delta: 8.72(\mathrm{~d}, \mathrm{~J}=5.3 \mathrm{~Hz}, 2$ $\mathrm{H}), 7.81(\mathrm{q}, \mathrm{J}=8.2 \mathrm{~Hz}, 6 \mathrm{H}), 7.71(\mathrm{~d}, \mathrm{~J}=8.6 \mathrm{~Hz}, 2 \mathrm{H}), 7.68(\mathrm{~d}$, $\mathrm{J}=7.6 \mathrm{~Hz}, 2 \mathrm{H}), 7.59(\mathrm{~d}, \mathrm{~J}=8.7 \mathrm{~Hz}, 2 \mathrm{H}), 7.47(\mathrm{~d}, \mathrm{~J}=7.6 \mathrm{~Hz}$, $2 \mathrm{H}), 7.41(\mathrm{t}, \mathrm{J}=7.4 \mathrm{~Hz}, 2 \mathrm{H}), 7.34(\mathrm{t}, \mathrm{J}=7.4 \mathrm{~Hz}, 1 \mathrm{H}), 7.09(\mathrm{~d}$, $\mathrm{J}=8.7 \mathrm{~Hz}, 2 \mathrm{H}), 5.14(\mathrm{~s}, 2 \mathrm{H})$.

ESI-HRMS: $m / z \quad[\mathrm{M}+\mathrm{H}]^{+}$calcd for $\mathrm{C}_{30} \mathrm{H}_{24} \mathrm{NO}$ : 414.18524; found: 414.18522 ( -0.1 ppm error).

4-(4'-(Benzyloxy)-[1,1'-biphenyl]-4-yl)-1-methylpyridinium iodide (12): In a $20 \mathrm{~mL}$ microwave vial with a magnetic stirrer was added $300 \mathrm{mg}$ ( $0.89 \mathrm{mmol}, 1.0$ equiv) of 4-(4'-(benzyloxy)-[1,1'-biphenyl]-4-yl)pyridine (10). The vial was capped and $15 \mathrm{~mL}$ of anhydrous DMF was cannulated followed by $0.3 \mathrm{~mL}$ ( $4.8 \mathrm{mmol}, 5.5$ equiv) of MeI. The reaction mixture was stirred at $60^{\circ} \mathrm{C}$ for $48 \mathrm{~h}$. After completion, a large amount of yellow solid was formed. To the reaction mixture $30 \mathrm{~mL}$ of diethyl ether was added and shook well. The product was filtered and dried under high vacuum at $100{ }^{\circ} \mathrm{C}$ overnight. The product was collected as $418 \mathrm{mg}$ (98\%) of yellow solid.

IR (solid, $\mathrm{cm}^{-1}$ ): 3014, 2934.7, 2872, 1909.2, 1638.2, $1592.6,1579.2,1539.9,1490.5,1466.1,1458.1,1406.2$, 1382.3, 1345.8, 1329.2, 1287, 1248.2, 1230.3, 1208, 1187.5, 1111.2, 1084.4, 1052.9, 1019.8, 1008.3, 996.4, 966.6, 944.7, 930.2, 867.9, 836.3, 813.7, 771.8, 742.1, 714.7, 703.3, 661.2.

${ }^{1} \mathrm{H}$ NMR (600 MHz, $\left.\mathrm{CD}_{3} \mathrm{OD}\right) \delta: 8.85(\mathrm{~d}, \mathrm{~J}=7.0 \mathrm{~Hz}, 2 \mathrm{H})$, $8.42(\mathrm{~d}, \mathrm{~J}=7.0 \mathrm{~Hz}, 2 \mathrm{H}), 8.08(\mathrm{~d}, \mathrm{~J}=8.5 \mathrm{~Hz}, 2 \mathrm{H}), 7.88(\mathrm{~d}$, $\mathrm{J}=8.5 \mathrm{~Hz}, 2 \mathrm{H}), 7.69(\mathrm{~d}, \mathrm{~J}=8.8 \mathrm{~Hz}, 2 \mathrm{H}), 7.47(\mathrm{~d}, \mathrm{~J}=6.9 \mathrm{~Hz}$, $2 \mathrm{H}), 7.39(\mathrm{t}, \mathrm{J}=7.6 \mathrm{~Hz}, 2 \mathrm{H}), 7.32(\mathrm{t}, \mathrm{J}=7.3 \mathrm{~Hz}, 1 \mathrm{H}), 7.14(\mathrm{~d}$, $\mathrm{J}=8.8 \mathrm{~Hz}, 2 \mathrm{H}), 5.17(\mathrm{~s}, 2 \mathrm{H}), 4.39(\mathrm{~s}, 3 \mathrm{H}) .{ }^{1} \mathrm{H}$ NMR

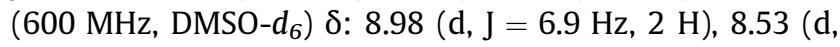
$\mathrm{J}=9.2 \mathrm{~Hz}, 2 \mathrm{H}), 8.16(\mathrm{~d}, \mathrm{~J}=8.5 \mathrm{~Hz}, 2 \mathrm{H}), 7.91(\mathrm{~d}, \mathrm{~J}=8.6 \mathrm{~Hz}$ $2 \mathrm{H}), 7.77$ (d, J = 8.7 Hz, $2 \mathrm{H}$ ), 7.48 (d, J = 7.8 Hz, $2 \mathrm{H}), 7.41$ $(\mathrm{t}, \mathrm{J}=7.6 \mathrm{~Hz}, 2 \mathrm{H}), 7.34(\mathrm{t}, \mathrm{J}=7.4 \mathrm{~Hz}, 1 \mathrm{H}), 7.16(\mathrm{~d}$, $\mathrm{J}=8.8 \mathrm{~Hz}, 2 \mathrm{H}), 5.19$ (s, $2 \mathrm{H}), 4.33$ (s, $3 \mathrm{H}$ ).

${ }^{13} \mathrm{CNMR}\left(151 \mathrm{MHz}\right.$, DMSO- $\left.d_{6}\right) \delta: 158.83,153.70,145.49$, $143.21,136.95,131.50,130.96,128.68,128.50,128.19$, 127.91, 127.69, 127.13, 123.64, 115.49, 69.33, 47.01.

ESI-HRMS: $m / z\left[\mathrm{M}-\mathrm{I}^{-}\right]^{+}$calcd for $\mathrm{C}_{25} \mathrm{H}_{22} \mathrm{NO}$ : 352.16959 ; found: 352.16976 (0.5 ppm error).

4-(4"-(Benzyloxy)-[1,1':4',1"-terphenyl]-4-yl)-1methylpyridinium iodide (13): In a $25 \mathrm{~mL}$ microwave vial with a magnetic stirrer was added $300 \mathrm{mg}(0.73 \mathrm{mmol}, 1.0$ equiv) of 4 -(4"-(benzyloxy)-[1,1':4',1"-terphenyl]-4-yl) pyridine (11). The vial was capped and $15 \mathrm{~mL}$ of anhydrous DMF was cannulated followed by transferring $0.2 \mathrm{~mL}$ (3.2 mmol, 4.4 equiv) of MeI. The reaction mixture was stirred at $100{ }^{\circ} \mathrm{C}$ for $48 \mathrm{~h}$. After completion, a large amount of yellow solid was formed. To the reaction mixture, $30 \mathrm{~mL}$ of diethyl ether was added and shook well. The product was filtered and dried under high vacuum at $100{ }^{\circ} \mathrm{C}$ overnight. The product was collected as $394 \mathrm{mg}$ (98\%) of yellow solid.

IR (solid, $\mathrm{cm}^{-1}$ ): 2993.7, 1637.4, 1597.1, 1580.6, 1560.6, 1525.7, 1487.7, 1470.3, 1459.3, 1450.9, 1427.3, 1402.6, 1378.8, 1341.1, 1315.8, 1290.5, 1251.3, 1231, 1219, 1199.2, $1185.5,1178.4,1163.9,1116,1040,1026.7,998.7,944.8$, 847.2, 834.6, 814.1, 806, 768.5, 745.2, 723.7, 716.3, 697.4.

${ }^{1} \mathrm{H}$ NMR $\left(600 \mathrm{MHz}\right.$, DMSO-d $\left.{ }_{6}\right) \delta: 9.01(\mathrm{~d}, \mathrm{~J}=7.0 \mathrm{~Hz}, 2$ $\mathrm{H}), 8.57(\mathrm{~d}, \mathrm{~J}=7.1 \mathrm{~Hz}, 2 \mathrm{H}), 8.21(\mathrm{~d}, \mathrm{~J}=8.5 \mathrm{~Hz}, 2 \mathrm{H}), 8.02(\mathrm{~d}$, $\mathrm{J}=8.6 \mathrm{~Hz}, 2 \mathrm{H}), 7.89(\mathrm{~d}, \mathrm{~J}=8.4 \mathrm{~Hz}, 2 \mathrm{H}), 7.78(\mathrm{~d}, \mathrm{~J}=8.5 \mathrm{~Hz}$, $2 \mathrm{H}$ ), 7.70 (d, J = 8.8 Hz, $2 \mathrm{H}$ ), 7.48 (d, J = 6.8 Hz, $2 \mathrm{H}$ ), 7.41 $(\mathrm{t}, \mathrm{J}=7.6 \mathrm{~Hz}, 2 \mathrm{H}), 7.35(\mathrm{t}, \mathrm{J}=7.3 \mathrm{~Hz}, 1 \mathrm{H}), 7.14(\mathrm{~d}$, $\mathrm{J}=8.9 \mathrm{~Hz}, 2 \mathrm{H}), 5.18(\mathrm{~s}, 2 \mathrm{H}), 4.34(\mathrm{~s}, 3 \mathrm{H})$.

${ }^{13} \mathrm{C}$ NMR $\left(151 \mathrm{MHz}, \mathrm{DMSO}-d_{6}\right) \delta: 158.25,153.65,145.54$, $143.06,139.81,137.03,136.71,132.22,131.86,128.74$, 
$128.47,127.78,127.66,127.52,127.40,126.80,123.77$, 115.35, 69.27, 54.40.

ESI-HRMS: $m / z$ [M-I- $]^{+}$calcd for $\mathrm{C}_{31} \mathrm{H}_{26} \mathrm{NO}: 428.20089$. Found: 428.20076 ( $-0.3 \mathrm{ppm}$ error).

4-(4'-Hydroxy-[1,1'-biphenyl]-4-yl)-1-methylpyridinium chloride [OPP(2)-OH]: In a $20 \mathrm{~mL}$ microwave vial with a magnetic stirrer were added $190 \mathrm{mg}(0.4 \mathrm{mmol}, 1.0$ equiv $)$ of 4-(4'-(benzyloxy)-[1,1'-biphenyl]-4-yl)-1-methylpyridinium iodide (12) and $10 \mathrm{~mL}$ (large excess) of hydrobromic acid solution (33 wt\% in acetic acid). The vial was capped and the reaction mixture was stirred at r.t. for 16 h. Conversion of benzyl group to the acetate functionality was confirmed by ESI-MS [positive mode; calculated $m / z$ for $[\mathrm{M}]^{+}: 304.13321$, found: 304.13299 ( $-0.3 \mathrm{ppm}$ error)]. After completion, the reaction mixture was dried under nitrogen flow and washed thoroughly with centrifugation using $3 \times 40 \mathrm{~mL}$ of DCM, $2 \times 5 \mathrm{~mL}$ of $1 \mathrm{~mol} / \mathrm{L}$ aqueous sodium metabisulfite solution, and $10 \mathrm{~mL}$ of water. The obtained solid was transferred to a $20 \mathrm{~mL}$ microwave vial with a magnetic stirrer followed by addition of $8 \mathrm{~mL}$ of $\mathrm{MeOH}$ and $1.5 \mathrm{~mL}$ of $32 \%$ aqueous $\mathrm{HCl}$. The vial was capped and the reaction mixture was stirred at $60^{\circ} \mathrm{C}$ for $16 \mathrm{~h}$. After completion, the reaction mixture was dried under nitrogen flow and washed consistently by centrifugation with $10 \mathrm{~mL}$ of water and $5 \mathrm{~mL}$ of $1 \mathrm{M}$ sodium metabisulfite solution. To the obtained solid was added $1 \mathrm{~mL}$ (excess) of $1 \mathrm{~mol} / \mathrm{L} \mathrm{NaOH}$ solution to ensure complete deprotonation and the mixture was sonicated. After discarding the excess of the base, the solid was treated with $1 \mathrm{~mL}$ of $1 \mathrm{~mol} / \mathrm{L} \mathrm{HCl}$ solution. After sonication excess of the acid was discarded, the solid was washed with $10 \mathrm{~mL}$ of water and dried. After drying in a vacuum oven overnight, $40 \mathrm{mg}$ (35\%) of yellow solid was obtained.

IR (film, $\mathrm{cm}^{-1}$ ): 3393.8, 2966.8, 1644.1, 1601.8, 1541, 1494.8, 1274.8, 1231.7, 1191.2, 1054.7, 1033.3, 813.1.

${ }^{1} \mathrm{H}$ NMR $\left(600 \mathrm{MHz}\right.$, DMSO- $\left.d_{6}\right) \delta: 9.77(\mathrm{~s}, 1 \mathrm{H}), 8.99(\mathrm{~d}$, $\mathrm{J}=6.3 \mathrm{~Hz}, 2 \mathrm{H}), 8.54(\mathrm{~d}, \mathrm{~J}=6.3 \mathrm{~Hz}, 2 \mathrm{H}), 8.14(\mathrm{~d}, \mathrm{~J}=8.1 \mathrm{~Hz}$, $2 \mathrm{H}), 7.87(\mathrm{~d}, \mathrm{~J}=8.1 \mathrm{~Hz}, 2 \mathrm{H}), 7.66(\mathrm{~d}, \mathrm{~J}=8.2 \mathrm{~Hz}, 2 \mathrm{H}), 6.90$ $(\mathrm{d}, \mathrm{J}=8.2 \mathrm{~Hz}, 2 \mathrm{H}), 4.32(\mathrm{~s}, 3 \mathrm{H}) .{ }^{1} \mathrm{H}$ NMR $\left(600 \mathrm{MHz}, \mathrm{CD}_{3} \mathrm{OD}\right)$ $\delta: ~ 8.84(\mathrm{~d}, \mathrm{~J}=6.9 \mathrm{~Hz}, 2 \mathrm{H}), 8.40(\mathrm{~d}, \mathrm{~J}=6.9 \mathrm{~Hz}, 2 \mathrm{H}), 8.06$ (d, $\mathrm{J}=8.6 \mathrm{~Hz}, 2 \mathrm{H}), 7.84(\mathrm{~d}, \mathrm{~J}=8.5 \mathrm{~Hz}, 2 \mathrm{H}), 7.60(\mathrm{~d}, \mathrm{~J}=8.7 \mathrm{~Hz}$, $2 \mathrm{H}), 6.91(\mathrm{~d}, \mathrm{~J}=8.6 \mathrm{~Hz}, 2 \mathrm{H}), 4.39(\mathrm{~s}, 3 \mathrm{H})$.

${ }^{13} \mathrm{C}$ NMR $\left(151 \mathrm{MHz}, \mathrm{CD}_{3} \mathrm{OD}\right) \delta: 159.46,157.13,146.48$, $146.43,132.65,131.61,129.59,129.32,128.49,125.18$, 116.97, 47.88.

ESI-HRMS: $m / z \quad\left[\mathrm{M}-\mathrm{Cl}^{-}\right]^{+}$calcd for $\mathrm{C}_{18} \mathrm{H}_{16} \mathrm{NO}$ : 262.12264; found: 262.12249 ( $-0.6 \mathrm{ppm}$ error).

4'-(1-Methylpyridin-1-ium-4-yl)-[1,1'-biphenyl]-4olate [OPP(2)-(-0 ${ }^{-}$]: In a $15 \mathrm{~mL}$ centrifuge vial, $20 \mathrm{mg}$ (0.04 mmol, 1 equiv) of 4-(4'-hydroxy-[1,1'-biphenyl]-4yl)-1-methylpyridinium chloride [OPP(2)-OH] and $1 \mathrm{~mL}$ ( $1 \mathrm{mmol}, 25$ equiv) of $1 \mathrm{~mol} / \mathrm{L} \mathrm{NaOH}$ solution were added. After sonication and centrifugation, excess of the base was discarded and the solid was washed with $5 \mathrm{~mL}$ of water and dried. After drying in a vacuum oven overnight, $17.2 \mathrm{mg}$ (98\%) of red solid was obtained.

IR (solid, $\mathrm{cm}^{-1}$ ): 3056.3, 1644.6, 1575.9, 1539.6, 1487.7, 1424.2, 1328.5, 1284.8, 1233.2, 1188, 1171.3, 1110.4, 989.6, 879.1, 851.5, 817.4, 743.7, 721.6.

${ }^{1} \mathrm{H}$ NMR (600 MHz, DMSO-d $\left.d_{6}\right) \delta: 8.83(\mathrm{~d}, \mathrm{~J}=6.5 \mathrm{~Hz}, 2$ $\mathrm{H}), 8.40(\mathrm{~d}, \mathrm{~J}=6.6 \mathrm{~Hz}, 2 \mathrm{H}), 8.01(\mathrm{~d}, \mathrm{~J}=8.5 \mathrm{~Hz}, 2 \mathrm{H}), 7.73(\mathrm{~d}$, $\mathrm{J}=8.2 \mathrm{~Hz}, 2 \mathrm{H}), 7.45(\mathrm{~d}, \mathrm{~J}=8.5 \mathrm{~Hz}, 2 \mathrm{H}), 6.46-6.41(\mathrm{~m}, 2 \mathrm{H})$, $4.28(\mathrm{~s}, 3 \mathrm{H}) .{ }^{1} \mathrm{H}$ NMR $\left(600 \mathrm{MHz}, \mathrm{CD}_{3} \mathrm{OD}\right) \delta: 8.63$ (d, $\mathrm{J}=6.9 \mathrm{~Hz}, 2 \mathrm{H}), 8.18(\mathrm{~d}, \mathrm{~J}=7.0 \mathrm{~Hz}, 2 \mathrm{H}), 7.84(\mathrm{~d}, \mathrm{~J}=8.6 \mathrm{~Hz}$, $2 \mathrm{H}), 7.65(\mathrm{~d}, \mathrm{~J}=8.6 \mathrm{~Hz}, 2 \mathrm{H}), 7.39(\mathrm{~d}, \mathrm{~J}=8.7 \mathrm{~Hz}, 2 \mathrm{H}), 6.66$ (d, J = 8.6 Hz, $2 \mathrm{H}), 4.28(\mathrm{~s}, 3 \mathrm{H})$.

ESI-HRMS: $\quad \mathrm{m} / \mathrm{z} \quad[\mathrm{M}+\mathrm{H}]^{+}$calcd for $\mathrm{C}_{18} \mathrm{H}_{16} \mathrm{NO}$ : 262.12264; found: 262.12266 ( $+0.1 \mathrm{ppm}$ error).

4-(4"-Hydroxy-[1,1':4',1"-terphenyl]-4-yl)-1-methylpyridinium chloride [OPP(3)-OH]: In a $20 \mathrm{~mL}$ microwave vial with a magnetic stirrer were added $230 \mathrm{mg}(0.4 \mathrm{mmol}, 1.0$ equiv) of 4-(4"-(benzyloxy)-[1,1':4',1"-terphenyl]-4-yl)-1methylpyridinium iodide (13) and $15 \mathrm{~mL}$ (large excess) of hydrobromic acid solution (33 wt\% in acetic acid). The vial was capped and the reaction mixture was stirred at r.t. for $16 \mathrm{~h}$. Conversion of benzyl group to the acetate functionality was confirmed by ESI-MS [positive mode; calculated $\mathrm{m} / \mathrm{z}$ for $[\mathrm{M}]+$ : 380.16451 , found: 380.16458 (0.2 ppm error)]. After completion, the reaction mixture was dried under nitrogen flow and washed consistently by centrifugation with $3 \times 40 \mathrm{~mL}$ of DCM, $2 \times 5 \mathrm{~mL}$ of $1 \mathrm{~mol} /$ L sodium metabisulfite solution, and $10 \mathrm{~mL}$ of water. The obtained solid was transferred to a $20 \mathrm{~mL}$ microwave vial with a magnetic stirrer followed by addition of $15 \mathrm{~mL}$ of $\mathrm{MeOH}$ and $1.5 \mathrm{~mL}$ of $32 \%$ aqueous $\mathrm{HCl}$. The vial was capped and the reaction mixture was stirred at $60{ }^{\circ} \mathrm{C}$ for $16 \mathrm{~h}$. After completion, the reaction mixture was dried under nitrogen flow and washed thoroughly with centrifugation using $10 \mathrm{~mL}$ of water and $5 \mathrm{~mL}$ of $1 \mathrm{M}$ sodium metabisulfite solution. To the obtained solid was added $1 \mathrm{~mL}$ (excess) of $1 \mathrm{~mol} / \mathrm{L} \mathrm{NaOH}$ solution to ensure complete deprotonation and the mixture was sonicated. After discarding the excess of the base, the solid was treated with $1 \mathrm{~mL}$ of $1 \mathrm{~mol} / \mathrm{L} \mathrm{HCl}$ solution. After sonication excess of the acid was discarded, the solid was washed with $10 \mathrm{~mL}$ of water and dried. After drying in a vacuum oven overnight, $114 \mathrm{mg}$ (76\%) of yellow solid was obtained.

IR (solid, $\mathrm{cm}^{-1}$ ): 3365.3, 3035.1, 2586.3, 1916.9, 1640, 1597.3,1526.3, 1488.5, 1401.4,1343.1,1278.4,1222.4,1199.4, 1173.4, 1108.4, 1044.8, 1000.4, 851, 808.7, 768.3, 728.3,710.4.

${ }^{1} \mathrm{H}$ NMR $\left(600 \mathrm{MHz}\right.$, DMSO-d $\left.\mathrm{d}_{6}\right) \delta: 9.02(\mathrm{~d}, \mathrm{~J}=6.4 \mathrm{~Hz}, 2$ H), $8.57(\mathrm{~d}, \mathrm{~J}=6.9 \mathrm{~Hz}, 2 \mathrm{H}), 8.20(\mathrm{~d}, \mathrm{~J}=8.5 \mathrm{~Hz}, 2 \mathrm{H}), 8.00(\mathrm{~d}$, $\mathrm{J}=8.4 \mathrm{~Hz}, 2 \mathrm{H}), 7.87(\mathrm{~d}, \mathrm{~J}=8.4 \mathrm{~Hz}, 2 \mathrm{H}), 7.74(\mathrm{~d}, \mathrm{~J}=8.4 \mathrm{~Hz}$, $2 \mathrm{H}), 7.58(\mathrm{~d}, \mathrm{~J}=8.5 \mathrm{~Hz}, 2 \mathrm{H}), 6.89(\mathrm{~d}, \mathrm{~J}=8.5 \mathrm{~Hz}, 2 \mathrm{H}), 4.34$ (s, $3 \mathrm{H})$.

${ }^{13}$ C NMR (151 MHz, DMSO- $\left.d_{6}\right) \delta: 157.45,153.64,145.53$, $143.11,140.25,136.27,132.11,129.99,128.72,127.73$, 127.44, 127.32, 126.52, 123.73, 115.82, 47.00 . 
ESI-HRMS: $m / z \quad\left[\mathrm{M}-\mathrm{Cl}^{-}\right]^{+}$calcd for $\mathrm{C}_{24} \mathrm{H}_{20} \mathrm{NO}$ : 338.15394; found: 338.15373 (-0.6 ppm error).

4"-(1-Methylpyridin-1-ium-4-yl)-[1,1':4',1"-terphenyl]-4-olate [OPP(3)-0 $\mathbf{0}^{-}$: In a $15 \mathrm{~mL}$ centrifuge vial, $20 \mathrm{mg}$ (0.05 mmol, 1 equiv) of 4-(4"-hydroxy-[1,1':4',1"terphenyl]-4-yl)-1-methylpyridinium chloride [OPP(3)$\mathbf{O H}$ ] and $1 \mathrm{~mL}$ ( $1 \mathrm{mmol}, 20$ equiv) of $1 \mathrm{~mol} / \mathrm{L} \mathrm{NaOH}$ solution were added. After sonication and centrifugation, excess of the base was discarded and the solid was washed with $5 \mathrm{~mL}$ of water and dried. After drying in a vacuum oven overnight, $16.7 \mathrm{mg}(93 \%)$ of purple solid was obtained.

IR (solid, $\mathrm{cm}^{-1}$ ): 3049.8, 2276.1, 1642.2, 1574.8, 1525.2, 1504.7, 1483.8, 1403.9, 1319.7, 1301.9, 1280.4, 1234.8, $1223.1,1203.2,1186.8,1171.9,1108.2,989.9,880.3,845.8$, 811, 768.9, 728.2.

ESI-HRMS: $m / z \quad[\mathrm{M}+\mathrm{H}]^{+}$calcd for $\mathrm{C}_{24} \mathrm{H}_{20} \mathrm{NO}$ : 338.15394; found: 338.15396 ( +0.1 ppm error).

\section{Funding Information}

This work was funded by the Australian Research Council through the ARC Centre of Excellence in Exciton Science (CE170100026).

\section{Acknowledgment}

IZ and TCO thank the University of Melbourne for scholarship support. We gratefully acknowledge the Australian Synchrotron for beamtime via the Collaborative Access Program (proposal number 13618b). The authors acknowledge access to the Mass Spectrometry and Proteomics Facility (MSPF) at the Bio21 Institute, University of Melbourne.

\section{Supporting Information}

Supporting Information for this article is available online at https://doi.org/10.1055/s-0041-1725075.

\section{References}

(1) Fort, A.; Boeglin, A.; Mager, L.; Amyot, C.; Combellas, C.; Thiébault, A.; Rodriguez, V. Synth. Met. 2001, 124, 209.

(2) Boeglin, A.; Fort, A.; Mager, L.; Combellas, C.; Thiébault, A.; Rodriguez, V. Chem. Phys. 2002, 282, 353.

(3) Reichardt, C. Chem. Rev. 1994, 94, 2319.

(4) He, G. S.; Zhu, J.; Baev, A.; Samoć, M.; Frattarelli, D. L.; Watanabe, N.; Facchetti, A.; Ågren, H.; Marks, T. J.; Prasad, P. N. J. Am. Chem. Soc. 2011, 133, 6675.

(5) Marder, S. R.; Kippelen, B.; Jen, A. K.-Y.; Peyghambarian, N. Nature 1997, 388, 845.

(6) Diemer, V.; Chaumeil, H.; Defoin, A.; Fort, A.; Boeglin, A.; Carré, C. Eur. J. Org. Chem. 2006, 2727.
(7) Shi, Y.; Frattarelli, D.; Watanabe, N.; Facchetti, A.; Cariati, E.; Righetto, S.; Tordin, E.; Zuccaccia, C.; Macchioni, A.; Wegener, S. L.; Stern, C. L.; Ratner, M. A.; Marks, T. J. J. Am. Chem. Soc. 2015 137, 12521.

(8) Yamaguchi, I.; Yamaji, R. J. Phys. Org. Chem. 2017, 30, e3671.

(9) Yamaguchi, I.; Goto, K.; Sato, M. Tetrahedron 2009, 65, 3645.

(10) Brooker, L.; Keyes, G.; Heseltine, D. J. Am. Chem. Soc. 1951, 73, 5350.

(11) Morley, J. O.; Morley, R. M.; Docherty, R.; Charlton, M. H. J. Am. Chem. Soc. 1997, 119, 10192.

(12) Rezende, M. C. J. Phys. Org. Chem. 2016, 29, 460.

(13) Catalan, J.; Mena, E.; Meutermans, W.; Elguero, J. J. Phys. Chem. 1992, 96, 3615.

(14) Diemer, V.; Chaumeil, H.; Defoin, A.; Jacques, P.; Carré, C. Tetrahedron Lett. 2005, 46, 4737.

(15) Machado, V. G.; Stock, R. I.; Reichardt, C. Chem. Rev. 2014, 114, 10429.

(16) Robert, F.; Winum, J.-Y.; Sakai, N.; Gerard, D.; Matile, S. Org. Lett. 2000, 2, 37.

(17) Martin, R. E.; Diederich, F. Angew. Chem. Int. Ed. 1999, 38, 1350.

(18) Arnaud-Neu, F.; Delgado, R.; Chaves, S. Pure Appl.Chem. 2003, 75, 71.

(19) Li, Z. H.; Wong, M. S.; Tao, Y.; D'Iorio, M. J. Org. Chem. 2004, 69, 921.

(20) Ahn, K.-H.; Ryu, G. Y.; Youn, S.-W.; Shin, D.-M. Mater. Sci. Eng., C 2004, 24, 163.

(21) Cheng, Y.-J.; Luh, T.-Y. J. Organomet. Chem. 2004, 689, 4137.

(22) Miyaura, N.; Yamada, K.; Suzuki, A. Tetrahedron Lett. 1979, 20, 3437.

(23) Barder, T. E.; Walker, S. D.; Martinelli, J. R.; Buchwald, S. L. J. Am. Chem. Soc. 2005, 127, 4685.

(24) Lennox, A. J.; Lloyd-Jones, G. C. Chem. Soc. Rev. 2014, 43, 412.

(25) Vogel, M. A.; Stark, C. B.; Lyapkalo, I. M. Synlett 2007, 2907.

(26) Hoegermeier, J.; Reißig, H. U. Chem. Eur. J. 2007, 13, 2410.

(27) Rottländer, M.; Knochel, P. J. Org. Chem. 1998, 63, 203.

(28) Blettner, C. G.; König, W. A.; Stenzel, W.; Schotten, T.J. Org. Chem. 1999, 64, 3885.

(29) Dominguez, M.; Reissig, H.-U. Synthesis 2014, 46, 1100.

(30) Lou, S.; Fu, G. C. Adv. Synth. Catal. 2010, 352, 2081.

(31) Kudo, N.; Perseghini, M.; Fu, G. C. Angew. Chem. Int. Ed. 2006, 45, 1282.

(32) Lott, R. S.; Chauhan, V. S.; Stammer, C. H. J. Chem. Soc., Chem. Commun. 1979, 495.

(33) Sajiki, H.; Kuno, H.; Hirota, K. Tetrahedron Lett. 1997, 38, 399.

(34) Sun, Z.; Zhou, T.; Pan, X.; Yang, Y.; Huan, Y.; Xiao, Z.; Shen, Z.; Liu, Z. Bioorg. Med. Chem. Lett. 2018, 28, 3050.

(35) Chouhan, M.; Kumar, K.; Sharma, R.; Grover, V.; Nair, V. A. Tetrahedron Lett. 2013, 54, 4540.

(36) Greene, T. W. Greene's Protective Groups in Organic Synthesis, 5th ed. John Wiley \& Sons, Inc.: Hoboken, New Jersey, 2014, 475.

(37) Bäuerle, P.; Würthner, F.; Heid, S. Angew. Chem. Int. Ed. Engl. 1990, 29, 419.

(38) Chaumeil, H.; Neuburger, M.; Jacques, P.; Tschamber, T.; Diemer, V.; Carré, C. Tetrahedron 2014, 70, 3116.

(39) (a) X-ray crystallographic data for compound $\left[\mathbf{O P P}(2)-\mathbf{O}^{-}\right]_{2} \cdot \mathbf{H C l}$ were deposited in the Cambridge Crystallographic Data Centre (CCDC) with identification number 2055376. (b) X-ray crystallographic data for compound $\mathbf{O P P}(\mathbf{3})$-OH were deposited in the Cambridge Crystallographic Data Centre (CCDC) with identification number 2055377.

(40) Jacques, P.; Graff, B.; Diemer, V.; Ay, E.; Chaumeil, H.; Carré, C.; Malval, J.-P. Chem. Phys. Lett. 2012, 531, 242.

(41) Effenberger, F.; Wuerthner, F.; Steybe, F.J. Org. Chem. 1995, 60, 2082. 
(42) Würthner, F.; Yao, S.; Debaerdemaeker, T.; Wortmann, R. J. Am. Chem. Soc. 2002, 124, 9431.

(43) Albert, I. D. L.; Marks, T. J.; Ratner, M. A. J. Am. Chem. Soc. 1998, 120 , 11174.

(44) Fabian, J.; Rosquete, G.; Montero-Cabrera, L. J. Mol. Struct. THEOCHEM 1999, 469, 163.

(45) Pati, S. K.; Marks, T.J.; Ratner, M. A.J.Am. Chem.Soc. 2001, $123,7287$.

(46) Mennucci, B. Phys. Chem. Chem. Phys. 2013, 15, 6583.

(47) Mennucci, B.; Cappelli, C.; Guido, C. A.; Cammi, R.; Tomasi, J. J. Phys. Chem. A 2009, 113, 3009.

(48) Meng, S.; Caprasecca, S.; Guido, C. A.; Jurinovich, S.; Mennucci, B. Theor. Chem. Acc. 2015, 134, 150.

(49) Frisch, M. J.; Trucks, G. W.; Schlegel, H. B.; Scuseria, G. E.; Robb, M. A.; Cheeseman, J. R.; Scalmani, G.; Barone, V.; Petersson, G. A.; Nakatsuji, H.; Li, X.; Caricato, M.; Marenich, A. V.; Bloino, J.; Janesko, B. G.; Gomperts, R.; Mennucci, B.; Hratchian, H. P.; Ortiz, J. V.; Izmaylov, A. F.; Sonnenberg, J. L.; Williams-Young, D.; Ding, F.; Lipparini, F.; Egidi, F.; Goings, J.; Peng, B.; Petrone, A.; Henderson, T.; Ranasinghe, D.; Zakrzewski, V. G.; Gao, J.; Rega, N.; Zheng, G.; Liang, W.; Hada, M.; Ehara, M.; Toyota, K.; Fukuda, R.; Hasegawa, J.; Ishida, M.; Nakajima, T.; Honda, Y.; Kitao, O.; Nakai, H.; Vreven, T.; Throssell, K.; Montgomery, J. A. Jr.; Peralta, J. E.; Ogliaro, F.; Bearpark, M. J.; Heyd, J. J.; Brothers, E. N.; Kudin, K. N.; Staroverov, V. N.; Keith, T. A.; Kobayashi, R.; Normand, J.; Raghavachari, K.; Rendell, A. P.; Burant, J. C.; Iyengar, S. S.;
Tomasi, J.; Cossi, M.; Millam, J. M.; Klene, M.; Adamo, C.; Cammi, R.; Ochterski, J. W.; Martin, R. L.; Morokuma, K.; Farkas, O.; Foresman, J. B.; Fox, D. J. Gaussian 16, Revision B. 01. Gaussian Inc.: Wallingford, CT, 2016.

(50) Lyapkalo, I.; Vogel, M.; Stark, C. Synlett 2007, 2907.

(51) Pangborn, A. B.; Giardello, M. A.; Grubbs, R. H.; Rosen, R. K.; Timmers, F. J. Organometallics 1996, 15, 1518.

(52) Cowieson, N. P.; Aragao, D.; Clift, M.; Ericsson, D. J.; Gee, C.; Harrop, S. J.; Mudie, N.; Panjikar, S.; Price, J. R.; RiboldiTunnicliffe, A.; Williamson, R.; Caradoc-Davies, T. J. Synchrotron Radiat. 2015, 22, 187.

(53) Sheldrick, G. M. Acta Crystallogr. Sect. C: Cryst. Struct. Commun. 2015, 71, 3.

(54) Farrugia, L. J. J. Appl. Crystallogr. 1997, 30, 565.

(55) Macrae, C. F.; Bruno, I. J.; Chisholm, J. A.; Edgington, P. R.; McCabe, P.; Pidcock, E.; Rodriguez-Monge, L.; Taylor, R.; Streek, J.; Wood, P. A. J. Appl. Crystallogr. 2008, 41, 466.

(56) Brindisi, M.; Butini, S.; Franceschini, S.; Brogi, S.; Trotta, F.; Ros, S.; Cagnotto, A.; Salmona, M.; Casagni, A.; Andreassi, M.; Saponara, S.; Gorelli, B.; Weikop, P.; Mikkelsen, J. D.; ScheelKruger, J.; Sandager-Nielsen, K.; Novellino, E.; Campiani, G.; Gemma, S. J. Med. Chem. 2014, 57, 9578.

(57) Prodanov, M. F.; Diakov, M. Y.; Vlasenko, G. S.; Vashchenko, V. V. Synlett 2015, 26, 1905. 